\title{
Solid-Phase Synthesis of
}

\section{Boranophosphate/Phosphorothioate/Phosphate Chimeric \\ Oligonucleotides and Their Potential as Antisense Oligonucleotides}

\author{
Yuhei Takahashi ${ }^{\dagger}$ Kazuki Sato ${ }^{\dagger *}$,Takeshi Wada ${ }^{\dagger *}$ \\ $\dagger$ Department of Medicinal and Life Science, Faculty of Pharmaceutical Sciences, \\ Tokyo University of Science, 2641 Yamazaki, Noda, Chiba 278-8510, Japan. \\ E-mail: kazuki sato@rs.tus.ac.jp,twada@rs.tus.ac.jp
}

Support information 


\section{Table of Contents}

RP-HPLC profiles of $\mathrm{T}_{\mathrm{PS}} \mathrm{T}$ dimer (Figure $\mathrm{S} 1$ )

RP-HPLC profiles of NPST dimers (Figure S2)

RP-HPLC profiles of $\mathrm{N}_{\mathrm{PB}} \mathrm{T}$ dimers (Figure $\mathrm{S} 3$ )

RP-HPLC profiles of tetramers (Figure S4)

RP-HPLC profiles of dodecamers (Figures S5-S18)

Thermal denaturation test (Figure S19-S20)

Nuclease resistance (Figure S21)

RNase $\mathrm{H}$ activity (25 U/mL, Figure S22)

RNase $\mathrm{H}$ activity (50 U/mL, Figure S23) 
RP-HPLC profiles of $T_{P S} T$ dimer (Table 1)
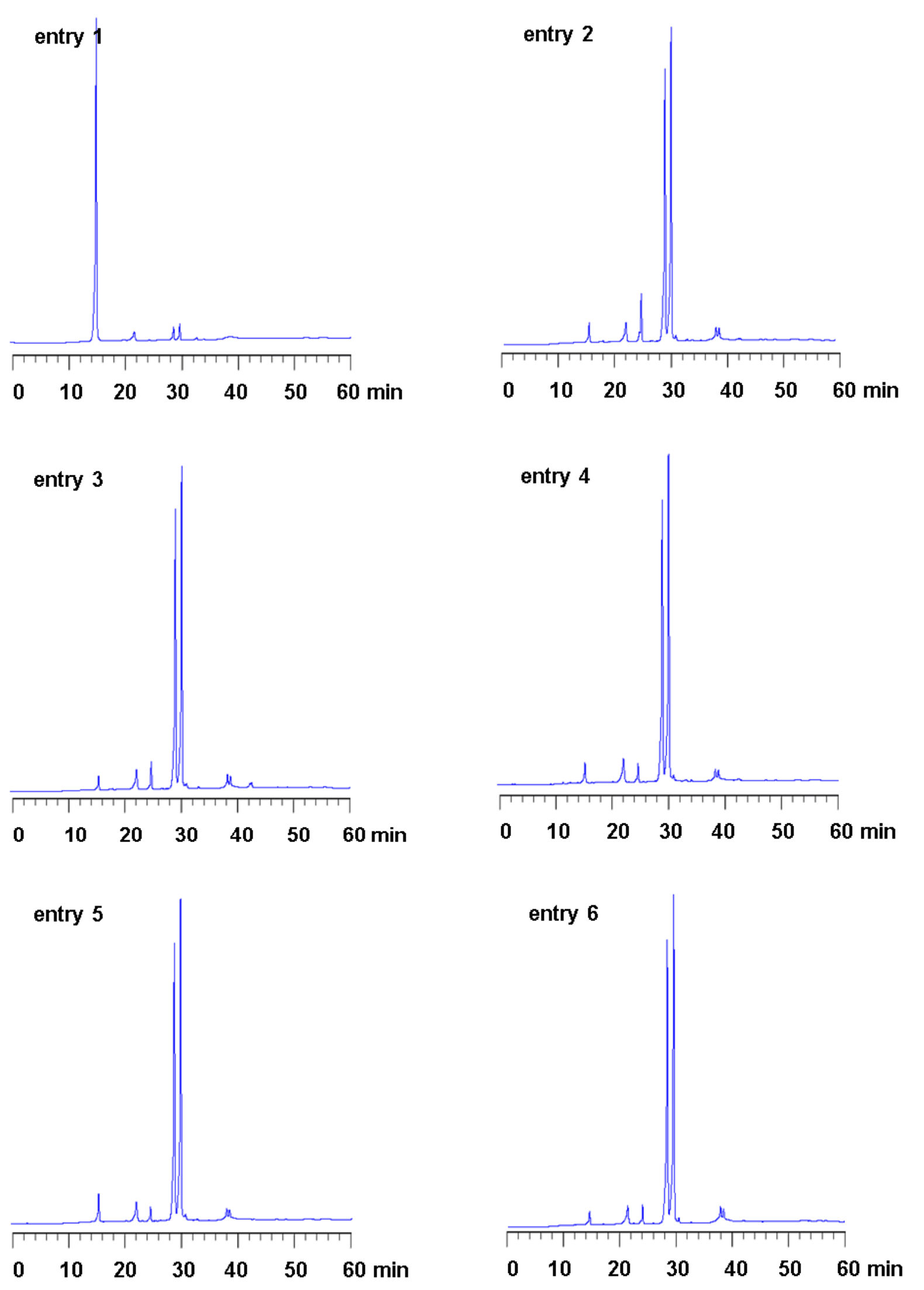


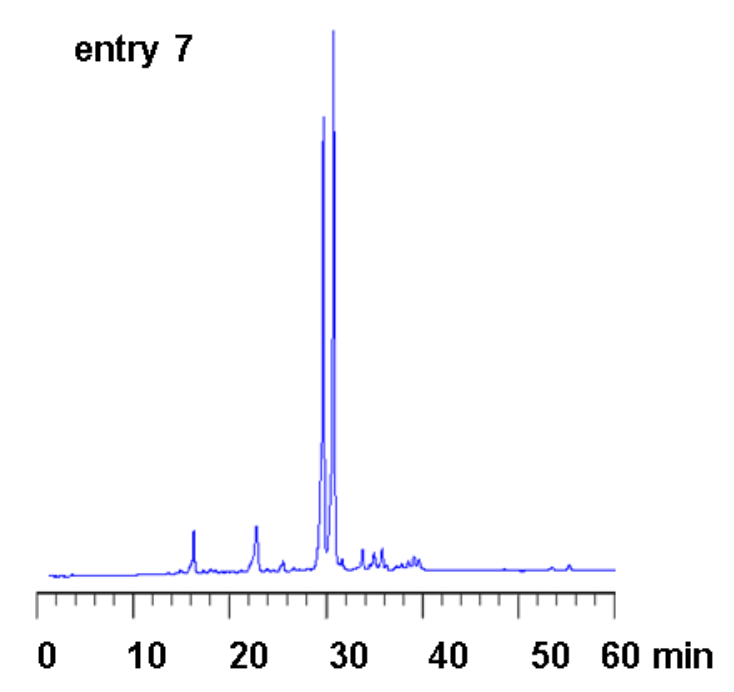

Figure S1. RP-HPLC profiles of crude $\mathrm{T}_{\mathrm{PS}} \mathrm{T}$. RP-HPLC was performed with a linear gradient of $0 \%-30 \%$ acetonitrile for 60 min in $0.1 \mathrm{M}$ triethylammonium acetate buffer $(\mathrm{pH} 7.0)$ at $30^{\circ} \mathrm{C}$ at a flow rate of $0.5 \mathrm{~mL} / \mathrm{min}$ using a $\mathrm{C} 18$ column. 
RP-HPLC profiles of BPST dimers (Table 2)
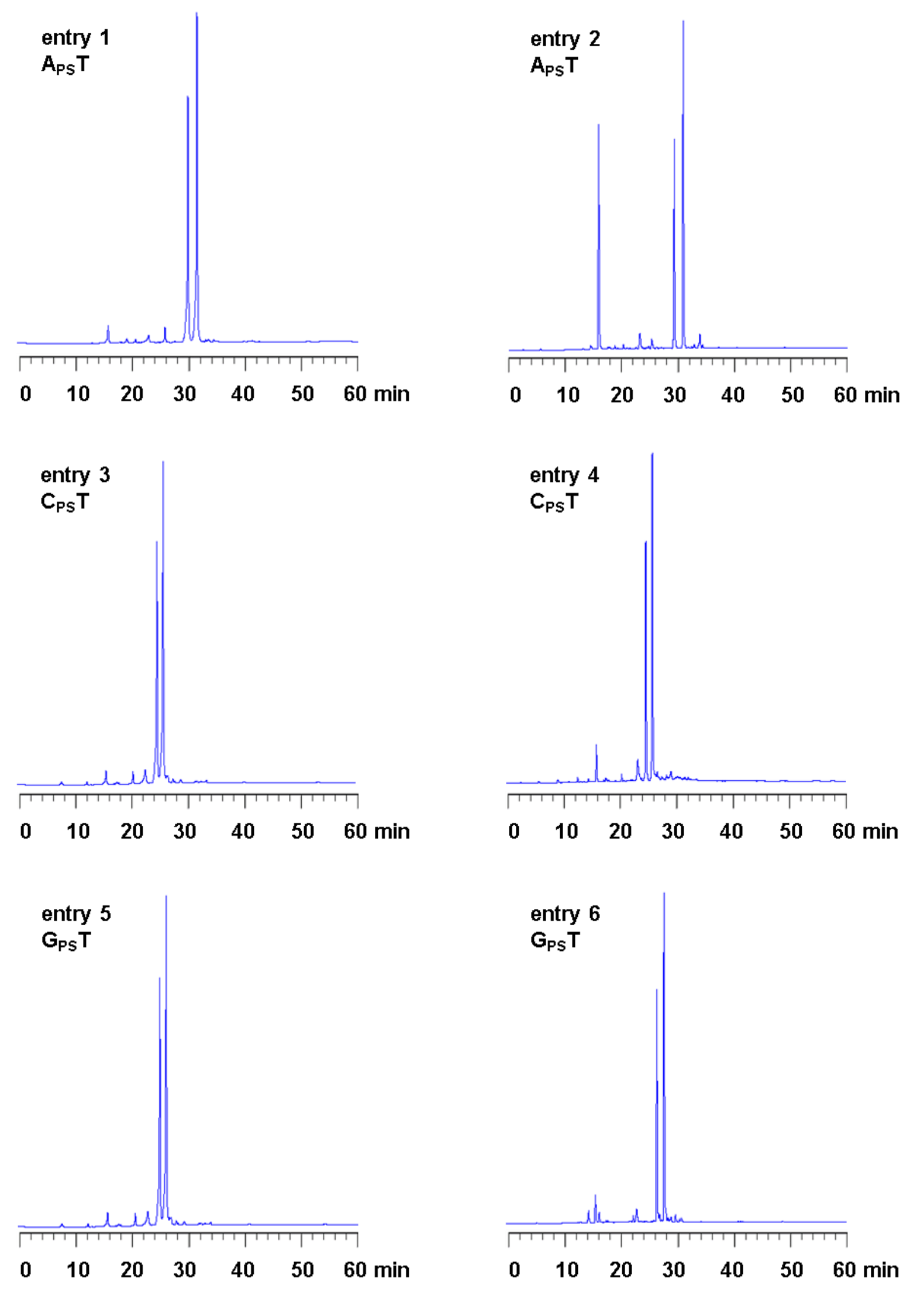


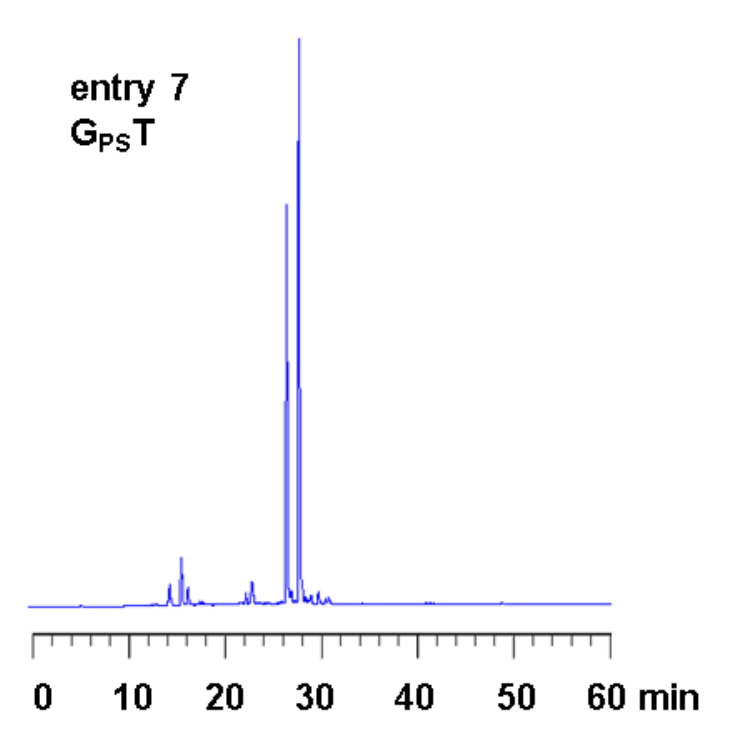

Figure S2. RP-HPLC profiles of crude BPST. RP-HPLC was performed with a linear gradient of $0 \%-30 \%$ acetonitrile for 60 $\min$ in $0.1 \mathrm{M}$ triethylammonium acetate buffer $(\mathrm{pH} 7.0)$ at $30^{\circ} \mathrm{C}$ at a flow rate of $0.5 \mathrm{~mL} / \mathrm{min}$ using a $\mathrm{C} 18$ column. 
RP-HPLC profiles of $\underline{B}_{P B} T$ dimers (Table 3)
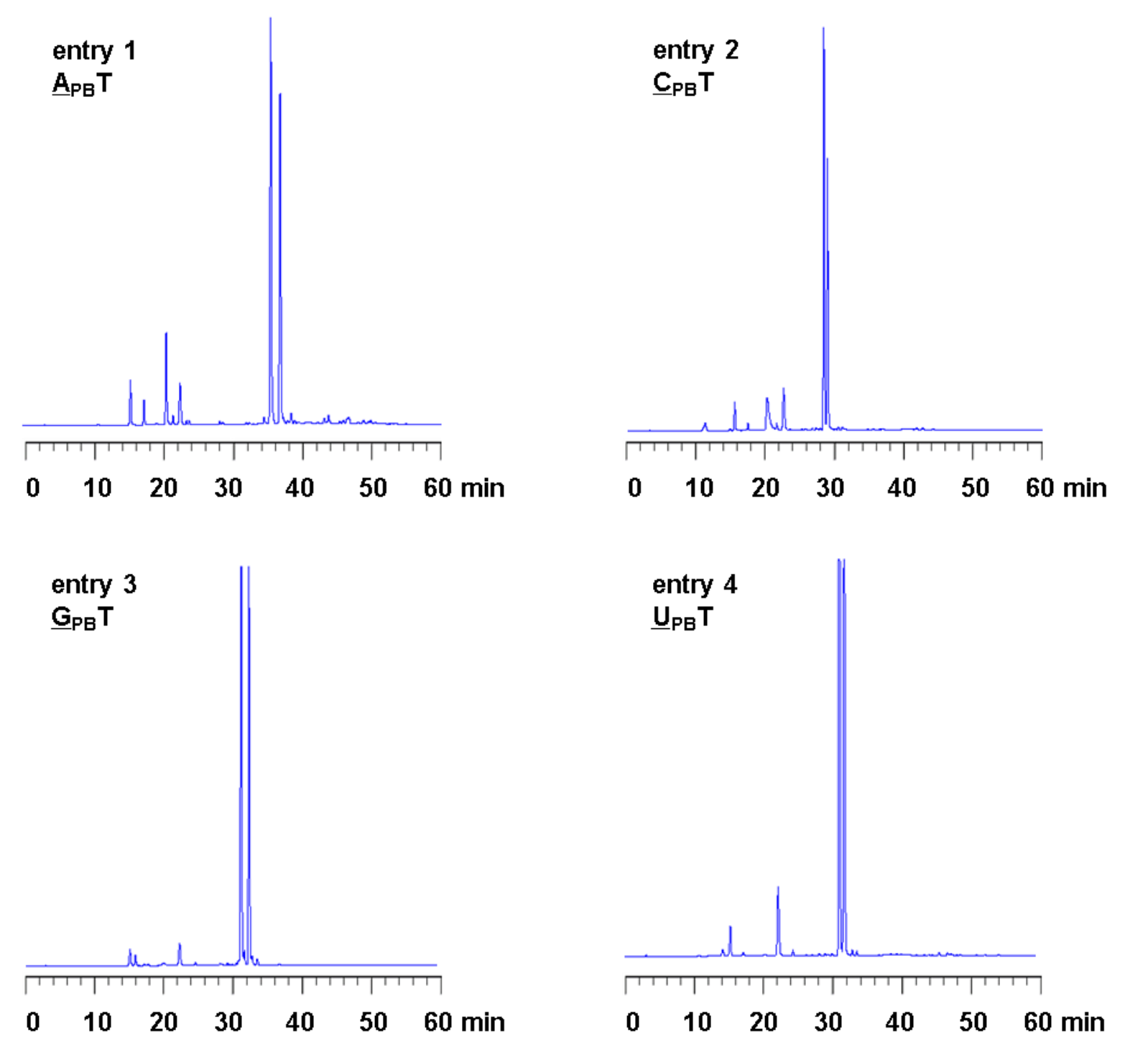

Figure S3. RP-HPLC profiles of crude $\mathrm{B}_{\mathrm{PB}} \mathrm{T}$. RP-HPLC was performed with a linear gradient of $0 \%-30 \%$ acetonitrile for 60 min in $0.1 \mathrm{M}$ triethylammonium acetate buffer $(\mathrm{pH} 7.0)$ at $30^{\circ} \mathrm{C}$ at a flow rate of $0.5 \mathrm{~mL} / \mathrm{min}$ using a $\mathrm{C} 18$ column. 
RP-HPLC profiles of tetramers (Table 4, entries 1 and 2)

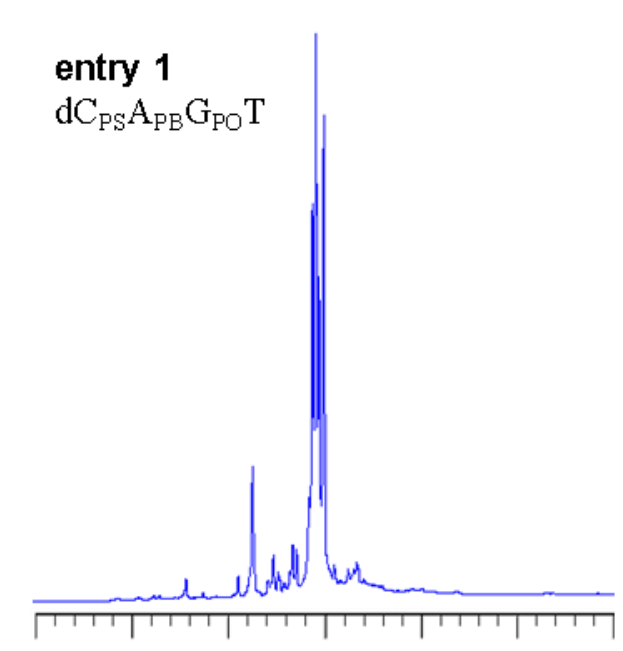

\section{$\begin{array}{lllllll}0 & 10 & 20 & 30 & 40 & 50 & 60\end{array} \mathbf{m i n}$}

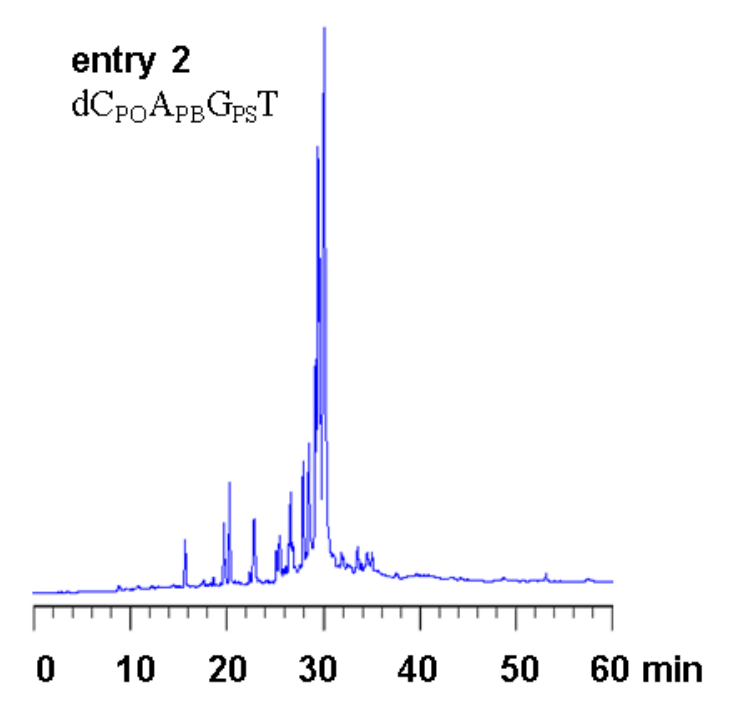

Figure S4. RP-HPLC profiles of crude tetramers ( $\mathrm{dC}_{\mathrm{PS}} \mathrm{A}_{\mathrm{PB}} \mathrm{G}_{\mathrm{PO}} \mathrm{T}$ and $\left.\mathrm{dC}_{\mathrm{PO}} \mathrm{A}_{\mathrm{PB}} \mathrm{G}_{\mathrm{PS}} \mathrm{T}\right)$. RP-HPLC was performed with a linear gradient of $0 \%-30 \%$ acetonitrile for $60 \mathrm{~min}$ in $0.1 \mathrm{M}$ triethylammonium acetate buffer $(\mathrm{pH} 7.0)$ at $30{ }^{\circ} \mathrm{C}$ at a flow rate of 0.5 $\mathrm{mL} / \mathrm{min}$ using a $\mathrm{C} 18$ column. 


\section{HPLC profiles of dodecamers (Table 4 entry 3)}

crude

$\mathrm{dC}_{\mathrm{PS}} A_{\mathrm{PS}} \mathrm{G}_{\mathrm{PS}} \mathrm{T}_{\mathrm{PS}} \mathrm{C}_{\mathrm{PE}} A_{\mathrm{PE}} \mathrm{G}_{\mathrm{PB}} \mathrm{T}_{\mathrm{PB}} \mathrm{C}_{\mathrm{PO}} A_{\mathrm{PO}} \mathrm{G}_{\mathrm{PO}} \mathrm{T}$

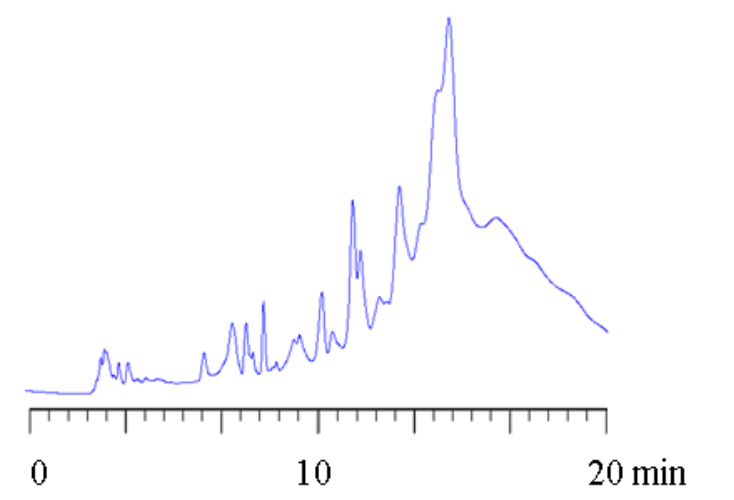

Figure S5. RP-HPLC profile of crude $d C_{P S} A_{P S} G_{P S} T_{P S} C_{P B} A_{P B} G_{P B} T_{P B} C_{P O} A_{P O} G P T$. RP-HPLC was performed with a linear gradient of $5 \%-40 \% \mathrm{MeOH}$ in $100 \mathrm{mM}$ HFIP, $8 \mathrm{mM}$ TEA for $20 \mathrm{~min}$ at $60{ }^{\circ} \mathrm{C}$ at a flow rate of $0.5 \mathrm{~mL} / \mathrm{min}$ using a $\mathrm{C} 18$ column.

pure

$\mathrm{dC}_{\mathrm{PS}} A_{\mathrm{PS}} \mathrm{G}_{\mathrm{PS}} \mathrm{T}_{\mathrm{PS}} \mathrm{C}_{\mathrm{PB}} A_{\mathrm{PB}} \mathrm{G}_{\mathrm{PB}} \mathrm{T}_{\mathrm{PB}} \mathrm{C}_{\mathrm{PO}} A_{\mathrm{PO}} \mathrm{G}_{\mathrm{PO}} \mathrm{T}$

RP-HPLC

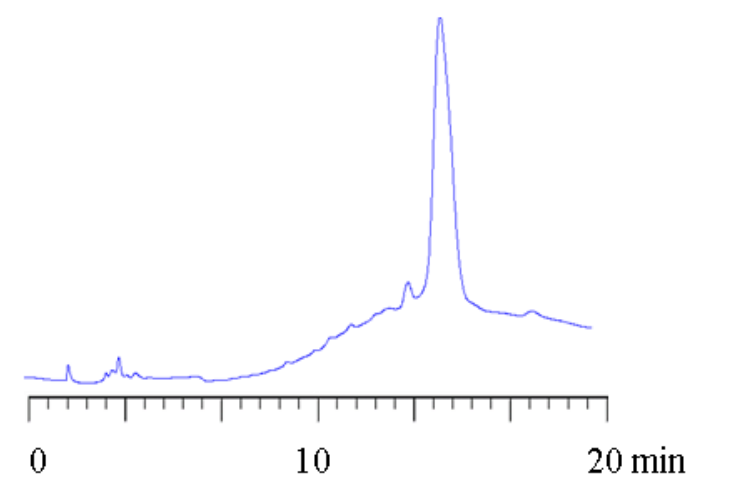

Figure S6. RP-HPLC profile of pure $\mathrm{dC}_{\mathrm{PS}} \mathrm{A}_{\mathrm{PS}} \mathrm{G}_{\mathrm{PS}} \mathrm{T}_{\mathrm{PS}} \mathrm{C}_{\mathrm{PB}} \mathrm{A}_{\mathrm{PB}} \mathrm{G}_{\mathrm{PB}} \mathrm{T}_{\mathrm{PB}} \mathrm{C}_{\mathrm{PO}} \mathrm{A}_{\mathrm{PO}} \mathrm{G}_{\mathrm{PO}} \mathrm{T}$. RP-HPLC was performed with a linear gradient of 5\%-40\% MeOH in $100 \mathrm{mM}$ HFIP, $8 \mathrm{mM}$ TEA for $20 \mathrm{~min}$ at $60{ }^{\circ} \mathrm{C}$ at a flow rate of $0.5 \mathrm{~mL} / \mathrm{min}$ using a $\mathrm{C} 18$ column. 


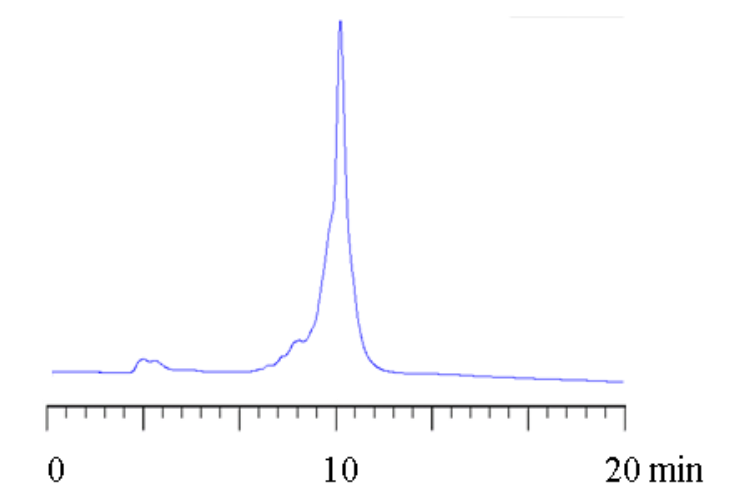

Figure S7. IE-HPLC profile of pure $d C_{P S} A_{P S} G_{P S} T_{P S} C_{P B} A_{P B} G_{P B} T_{P B} C_{P O} A_{P O} G_{P O} T$. IE-HPLC was performed with a linear gradient of $0 \mathrm{M}-1 \mathrm{M} \mathrm{NaClO}_{4}$ in $50 \%-25 \% \mathrm{CH}_{3} \mathrm{CN}, 10 \mathrm{mM}$ Tris- $\mathrm{HCl}(\mathrm{pH} 7.5)$ for $20 \mathrm{~min}$ at $30{ }^{\circ} \mathrm{C}$ with a flow rate of $0.4 \mathrm{~mL} / \mathrm{min}$ using a quaternary ammonium anion exchange resin column. 


\section{HPLC profiles of dodecamers (Table 4 entry 4)}

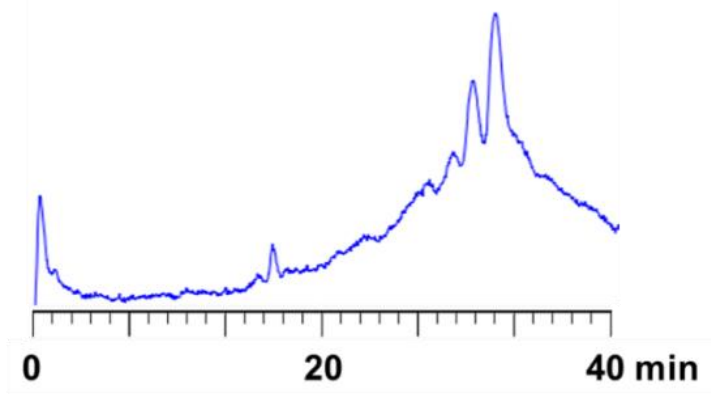

Figure S8. IE-HPLC profile of crude $\mathrm{dG}_{\mathrm{PB}} \mathrm{C}_{\mathrm{PS}} \mathrm{A}_{\mathrm{PB}} \mathrm{T}_{\mathrm{PO}} \mathrm{T}_{\mathrm{PO}} \mathrm{G}_{\mathrm{PO}} \mathrm{G}_{\mathrm{PO}} \mathrm{T}_{\mathrm{PS}} \mathrm{A}_{\mathrm{PB}} \mathrm{T}_{\mathrm{PS}} \mathrm{T}_{\mathrm{PB}} \mathrm{C}$. IE-HPLC was performed with a linear gradient of $0 \mathrm{M}-1 \mathrm{M} \mathrm{NaCl}$ in $30 \% i \mathrm{PrOH}, 10 \mathrm{mM}$ Tris- $\mathrm{HCl}(\mathrm{pH} 7.5)$ for $40 \mathrm{~min}$ at a flow rate of $0.4 \mathrm{~mL} / \mathrm{min}$ using a quaternary ammonium anion exchange resin column.

pure

$\mathrm{dG}_{\mathrm{PB}} \mathrm{C}_{\mathrm{PS}} A_{\mathrm{PB}} \mathrm{T}_{\mathrm{PO}} \mathrm{T}_{\mathrm{PO}} \mathrm{G}_{\mathrm{PO}} \mathrm{G}_{\mathrm{PO}} \mathrm{T}_{\mathrm{PS}} A_{\mathrm{PB}} \mathrm{T}_{\mathrm{PS}} \mathrm{T}_{\mathrm{PB}} \mathrm{C}$

RP-HPLC

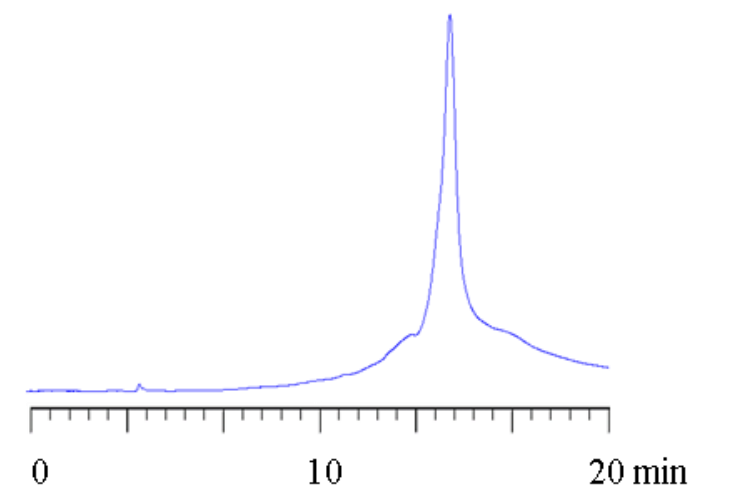

Figure S9. RP-HPLC profile of pure $\mathrm{dG}_{\mathrm{PB}} \mathrm{C}_{\mathrm{PS}} \mathrm{A}_{\mathrm{PB}} \mathrm{T}_{\mathrm{PO}} \mathrm{T}_{\mathrm{PO}} \mathrm{G}_{\mathrm{PO}} \mathrm{G}_{\mathrm{PO}} \mathrm{T}_{\mathrm{PS}} \mathrm{A}_{\mathrm{PB}} \mathrm{T}_{\mathrm{PS}} \mathrm{T}_{\mathrm{PB}} \mathrm{C}$. RP-HPLC was performed with a linear gradient of $5 \%-40 \% \mathrm{MeOH}$ in $100 \mathrm{mM}$ HFIP, $8 \mathrm{mM}$ TEA for $20 \mathrm{~min}$ at $60{ }^{\circ} \mathrm{C}$ at a flow rate of $0.5 \mathrm{~mL} / \mathrm{min}$ using a $\mathrm{C} 18$ column. 
pure

$\mathrm{dC}_{\mathrm{PS}} \mathrm{A}_{\mathrm{PS}} \mathrm{G}_{\mathrm{PS}} \mathrm{T}_{\mathrm{PS}} \mathrm{C}_{\mathrm{PB}} \mathrm{A}_{\mathrm{PB}} \mathrm{G}_{\mathrm{PB}} \mathrm{T}_{\mathrm{PB}} \mathrm{C}_{\mathrm{PO}} \mathrm{A}_{\mathrm{PO}} \mathrm{G}_{\mathrm{PO}} \mathrm{T}$

IE-HPLC

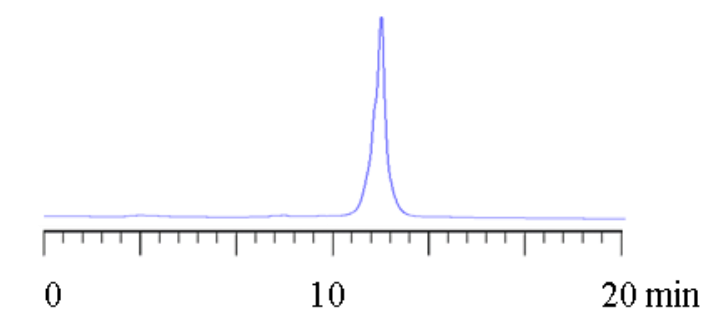

Figure S9. IE-HPLC profile of pure $\mathrm{dG}_{\mathrm{PB}} \mathrm{C}_{\mathrm{PS}} \mathrm{A}_{\mathrm{PB}} \mathrm{T}_{\mathrm{PO}} \mathrm{T}_{\mathrm{PO}} \mathrm{G}_{\mathrm{PO}} \mathrm{G}_{\mathrm{PO}} \mathrm{T}_{\mathrm{PS}} \mathrm{A}_{\mathrm{PB}} \mathrm{T}_{\mathrm{PS}} \mathrm{T}_{\mathrm{PB}} \mathrm{C}$. IE-HPLC was performed with a linear gradient of $0 \mathrm{M}-1 \mathrm{M} \mathrm{NaClO}_{4}$ in $50 \%-25 \% \mathrm{CH}_{3} \mathrm{CN}, 10 \mathrm{mM}$ Tris- $\mathrm{HCl}(\mathrm{pH}$ 7.5) for $20 \mathrm{~min}$ at $30{ }^{\circ} \mathrm{C}$ with a flow rate of $0.4 \mathrm{~mL} / \mathrm{min}$ using a quaternary ammonium anion exchange resin column. 


\section{HPLC profiles of dodecamers (Table 4 entry 5)}

crude

$\mathrm{dG}_{\mathrm{PB}} \mathrm{C}_{\mathrm{PS}} A_{\mathrm{PE}} \mathrm{T}_{\mathrm{PS}} \mathrm{T}_{\mathrm{PS}} \mathrm{G}_{\mathrm{PB}} \mathrm{G}_{\mathrm{PE}} \mathrm{T}_{\mathrm{PS}} A_{\mathrm{PE}} \mathrm{T}_{\mathrm{PS}} \mathrm{T}_{\mathrm{PB}} \mathrm{C}$

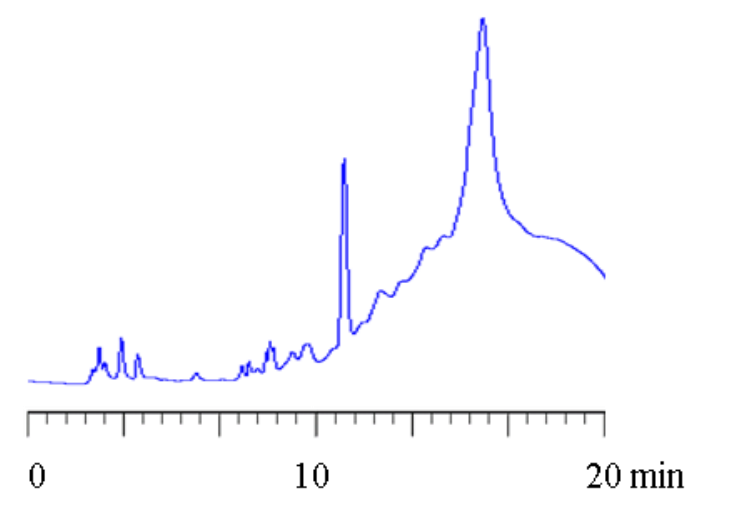

Figure S10. RP-HPLC profile of crude $d G_{P B} C_{P S} A_{P B} T_{P S} T_{P S} G_{P B} G_{P B} T_{P S} A_{P B} T_{P S} T_{P B} C$. RP-HPLC was performed with a linear gradient of $5 \%-40 \% \mathrm{MeOH}$ in $100 \mathrm{mM}$ HFIP, $8 \mathrm{mM}$ TEA for 20 min at $60{ }^{\circ} \mathrm{C}$ at a flow rate of $0.5 \mathrm{~mL} / \mathrm{min}$ using a $\mathrm{C} 18$ column.

pure

${d G_{P B}} C_{P S} A_{P B} T_{P S} T_{P S} G_{P B} G_{P B} T_{P S} A_{P B} T_{P S} T_{P B} C$

RP-HPLC

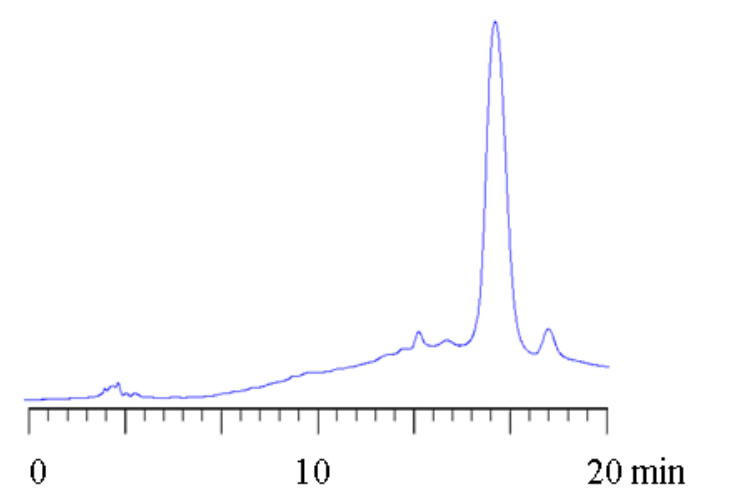

Figure S11. RP-HPLC profile of pure $\mathrm{dG}_{\mathrm{PB}} \mathrm{C}_{\mathrm{PS}} \mathrm{A}_{\mathrm{PB}} \mathrm{T}_{\mathrm{PS}} \mathrm{T}_{\mathrm{PS}} \mathrm{G}_{\mathrm{PB}} \mathrm{G}_{\mathrm{PB}} \mathrm{T}_{\mathrm{PS}} \mathrm{A}_{\mathrm{PB}} \mathrm{T}_{\mathrm{PS}} \mathrm{T}_{\mathrm{PB}} \mathrm{C}$. RP-HPLC was performed with a linear gradient of 5\%-40\% MeOH in $100 \mathrm{mM} \mathrm{HFIP}, 8 \mathrm{mM}$ TEA for $20 \mathrm{~min}$ at $60{ }^{\circ} \mathrm{C}$ at a flow rate of $0.5 \mathrm{~mL} / \mathrm{min}$ using a $\mathrm{C} 18$ column. 
pure

$\mathrm{dG}_{\mathrm{PB}} \mathrm{C}_{\mathrm{PS}} A_{\mathrm{PB}} \mathrm{T}_{\mathrm{PS}} \mathrm{T}_{\mathrm{PS}} \mathrm{G}_{\mathrm{PB}} \mathrm{G}_{\mathrm{PB}} \mathrm{T}_{\mathrm{PS}} A_{\mathrm{PB}} \mathrm{T}_{\mathrm{PS}} \mathrm{T}_{\mathrm{PB}} \mathrm{C}$

IE-HPLC

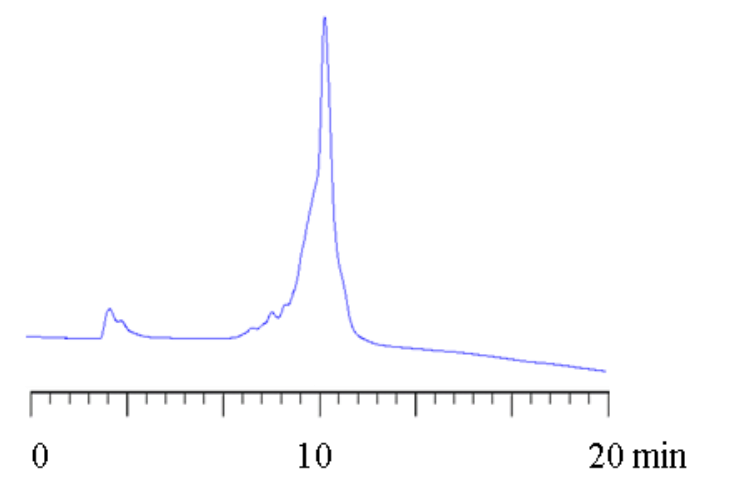

Figure S12. IE-HPLC profile of pure $\mathrm{dG}_{P B} \mathrm{C}_{P S} \mathrm{~A}_{\mathrm{PB}} \mathrm{T}_{\mathrm{PS}} \mathrm{T}_{\mathrm{PS}} \mathrm{G}_{\mathrm{PB}} \mathrm{G}_{\mathrm{PB}} \mathrm{T}_{\mathrm{PS}} \mathrm{A}_{\mathrm{PB}} \mathrm{T}_{\mathrm{PS}} \mathrm{T}_{\mathrm{PB}} \mathrm{C}$. IE-HPLC was performed with a linear gradient of $0 \mathrm{M}-1 \mathrm{M} \mathrm{NaClO}_{4}$ in $50 \%-25 \% \mathrm{CH}_{3} \mathrm{CN}, 10 \mathrm{mM}$ Tris- $\mathrm{HCl}(\mathrm{pH} 7.5)$ for $20 \mathrm{~min}$ at $30{ }^{\circ} \mathrm{C}$ with a flow rate of $0.4 \mathrm{~mL} / \mathrm{min}$ using a quaternary ammonium anion exchange resin column. 


\section{HPLC profiles of dodecamers (Table 4 entry 6)}

crude

$\mathrm{dG}_{\mathrm{PB}} \mathrm{C}_{\mathrm{PB}} A_{\mathrm{PB}} \mathrm{T}_{\mathrm{PO}} \mathrm{T}_{\mathrm{PO}} \mathrm{G}_{\mathrm{PO}} \mathrm{G}_{\mathrm{PO}} \mathrm{T}_{\mathrm{PB}} A_{\mathrm{PB}} \mathrm{T}_{\mathrm{PB}} \mathrm{T}_{\mathrm{PB}} \mathrm{C}$

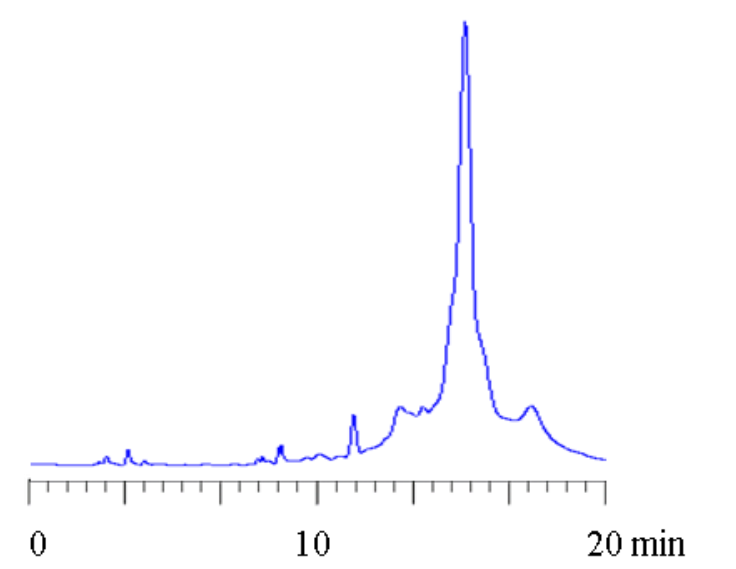

Figure S13. RP-HPLC profile of crude $\mathrm{dG}_{\mathrm{PB}} \mathrm{C}_{\mathrm{PB}} \mathrm{A}_{\mathrm{PB}} \mathrm{T}_{\mathrm{PO}} \mathrm{T}_{\mathrm{PO}} \mathrm{G}_{\mathrm{POO}} \mathrm{G}_{\mathrm{PO}} \mathrm{T}_{\mathrm{PB}} \mathrm{A}_{\mathrm{PB}} \mathrm{T}_{\mathrm{PB}} \mathrm{T}_{\mathrm{PB}} \mathrm{C}$. RP-HPLC was performed with a linear gradient of $5 \%-40 \% \mathrm{MeOH}$ in $100 \mathrm{mM} \mathrm{HFIP,} 8 \mathrm{mM}$ TEA for $20 \mathrm{~min}$ at $60{ }^{\circ} \mathrm{C}$ at a flow rate of $0.5 \mathrm{~mL} / \mathrm{min}$ using a $\mathrm{C} 18$ column.

pure

$\mathrm{dG}_{\mathrm{PB}} \mathrm{C}_{\mathrm{PB}} A_{\mathrm{PB}} \mathrm{T}_{\mathrm{PO}} \mathrm{T}_{\mathrm{PO}} \mathrm{G}_{\mathrm{PO}} \mathrm{G}_{\mathrm{PO}} \mathrm{T}_{\mathrm{PB}} A_{\mathrm{PB}} \mathrm{T}_{\mathrm{PB}} \mathrm{T}_{\mathrm{PB}} \mathrm{C}$ RP-HPLC

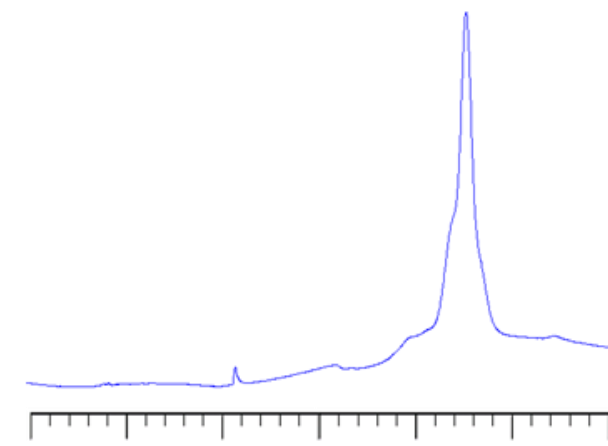

0 10 $20 \mathrm{~min}$

Figure S14. RP-HPLC profile of pure $\mathrm{dG}_{\mathrm{PB}} \mathrm{C}_{\mathrm{PB}} \mathrm{A}_{\mathrm{PB}} \mathrm{T}_{\mathrm{PO}} \mathrm{T}_{\mathrm{PO}} \mathrm{G}_{\mathrm{PO}} \mathrm{G}_{\mathrm{PO}} \mathrm{T}_{\mathrm{PB}} \mathrm{A}_{\mathrm{PB}} \mathrm{T}_{\mathrm{PB}} \mathrm{T}_{\mathrm{PB}} \mathrm{C}$. RP-HPLC was performed with a linear gradient of 5\%-40\% MeOH in $100 \mathrm{mM} \mathrm{HFIP,} 8 \mathrm{mM}$ TEA for 20 min at $60{ }^{\circ} \mathrm{C}$ at a flow rate of $0.5 \mathrm{~mL} / \mathrm{min}$ using a $\mathrm{C} 18$ column. 
pure

$\mathrm{dG}_{\mathrm{PB}} \mathrm{C}_{\mathrm{PE}} A_{\mathrm{PB}} \mathrm{T}_{\mathrm{PO}} \mathrm{T}_{\mathrm{PO}} \mathrm{G}_{\mathrm{PO}} \mathrm{G}_{\mathrm{PO}} \mathrm{T}_{\mathrm{PE}} A_{\mathrm{PB}} \mathrm{T}_{\mathrm{PB}} \mathrm{T}_{\mathrm{PE}} \mathrm{C}$

IE-HPLC

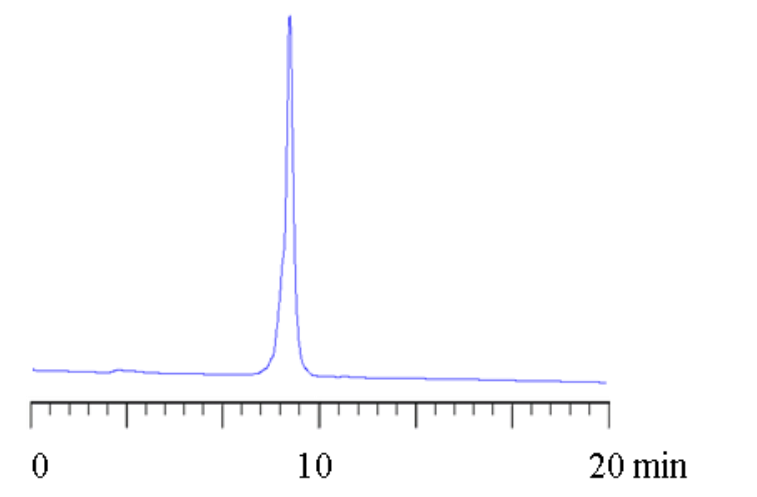

Figure S15. IE-HPLC profile of pure dG $\mathrm{GB}_{\mathrm{PB}} \mathrm{C}_{\mathrm{PB}} \mathrm{A}_{\mathrm{PB}} \mathrm{T}_{\mathrm{PO}} \mathrm{T}_{\mathrm{PO}} \mathrm{G}_{\mathrm{PO}} \mathrm{G}_{\mathrm{PO}} \mathrm{T}_{\mathrm{PB}} \mathrm{A}_{\mathrm{PB}} \mathrm{T}_{\mathrm{PB}} \mathrm{T}_{\mathrm{PB}} \mathrm{C}$. IE-HPLC was performed with a linear gradient of $0 \mathrm{M}-1 \mathrm{M} \mathrm{NaClO}_{4}$ in $50 \%-25 \% \mathrm{CH}_{3} \mathrm{CN}, 10 \mathrm{mM}$ Tris- $\mathrm{HCl}(\mathrm{pH} 7.5$ ) for 20 min at $30{ }^{\circ} \mathrm{C}$ with a flow rate of $0.4 \mathrm{~mL} / \mathrm{min}$ using a quaternary ammonium anion exchange resin column. 


\section{HPLC profiles of dodecamers (Table 4 entry 7)}

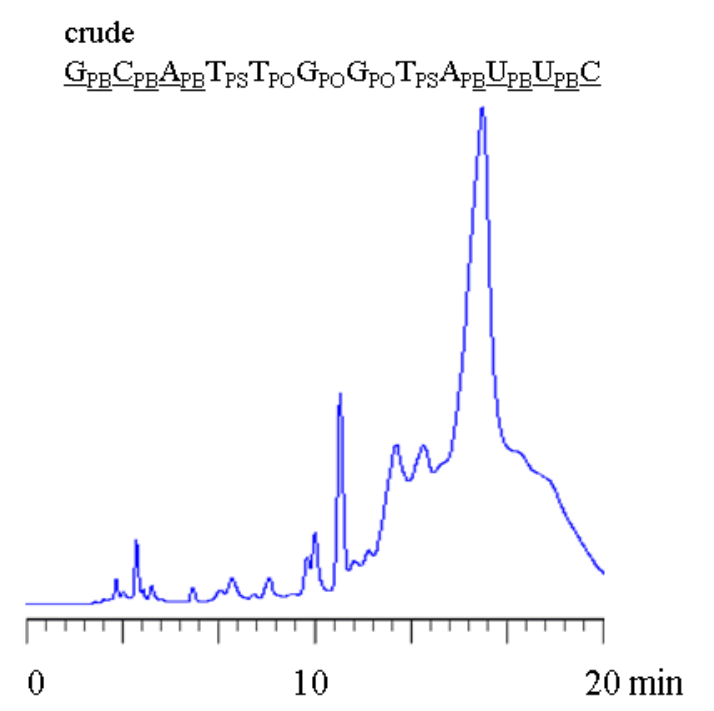

Figure S16. RP-HPLC profile of crude $\underline{G}_{P B} \underline{C}_{P B} \underline{A}_{P B} T_{P S} T_{P O} G_{P O} G_{P O} T_{P S} A_{P B} \underline{U}_{P B} \underline{U}_{P B} \underline{C}$. RP-HPLC was performed with a linear gradient of $5 \%-40 \% \mathrm{MeOH}$ in $100 \mathrm{mM}$ HFIP, $8 \mathrm{mM}$ TEA for $20 \mathrm{~min}$ at $60{ }^{\circ} \mathrm{C}$ at a flow rate of $0.5 \mathrm{~mL} / \mathrm{min}$ using a $\mathrm{C} 18$ column.
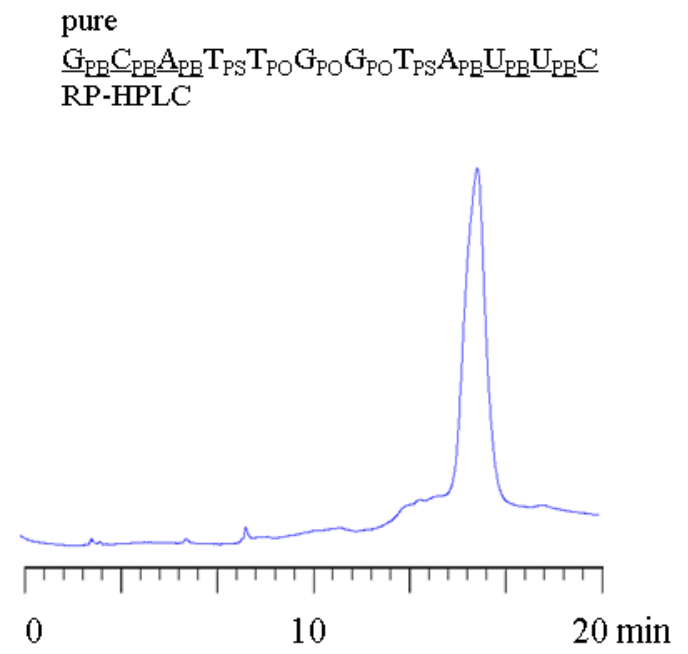

Figure S17. RP-HPLC profile of pure $\underline{G}_{P B} \underline{C}_{P B} \underline{A P B}_{P B} T_{P S} T_{P O} G_{P O} G_{P O} T_{P S} A_{P B} \underline{U}_{P B} \underline{U}_{P B} \underline{C}$. RP-HPLC was performed with a linear gradient of $5 \%-40 \% \mathrm{MeOH}$ in $100 \mathrm{mM}$ HFIP, $8 \mathrm{mM}$ TEA for $20 \mathrm{~min}$ at $60{ }^{\circ} \mathrm{C}$ at a flow rate of $0.5 \mathrm{~mL} / \mathrm{min}$ using a $\mathrm{C} 18$ column. 


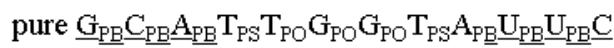

IE-HPLC

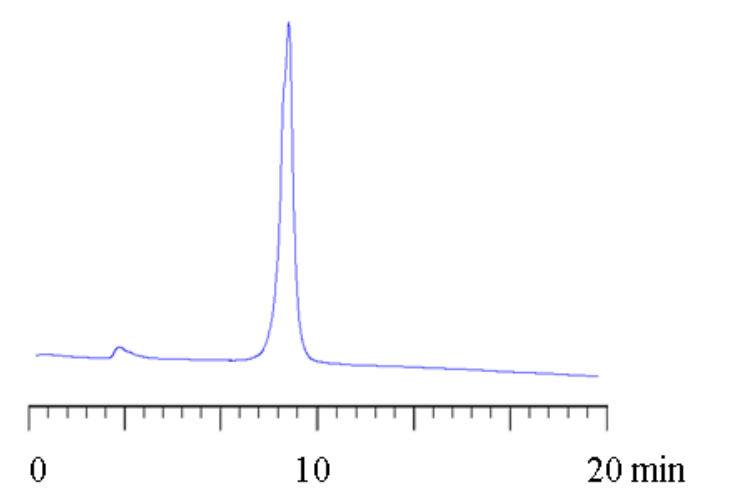

Figure S18. IE-HPLC profile of pure $\underline{G}_{p B} \underline{C}_{P B} \underline{A}_{P B} T_{P S} T_{P O} G_{P O} G_{P O} T_{P S} A_{P B} \underline{U}_{P B} \underline{U_{P B}} \underline{C}$. IE-HPLC was performed with a linear gradient of $0 \mathrm{M}-1 \mathrm{M} \mathrm{NaClO}_{4}$ in $50 \%-25 \% \mathrm{CH}_{3} \mathrm{CN}, 10 \mathrm{mM}$ Tris- $\mathrm{HCl}(\mathrm{pH} 7.5$ ) for 20 min at $30{ }^{\circ} \mathrm{C}$ with a flow rate of $0.4 \mathrm{~mL} / \mathrm{min}$ using a quaternary ammonium anion exchange resin column. 
Thermal denaturation test

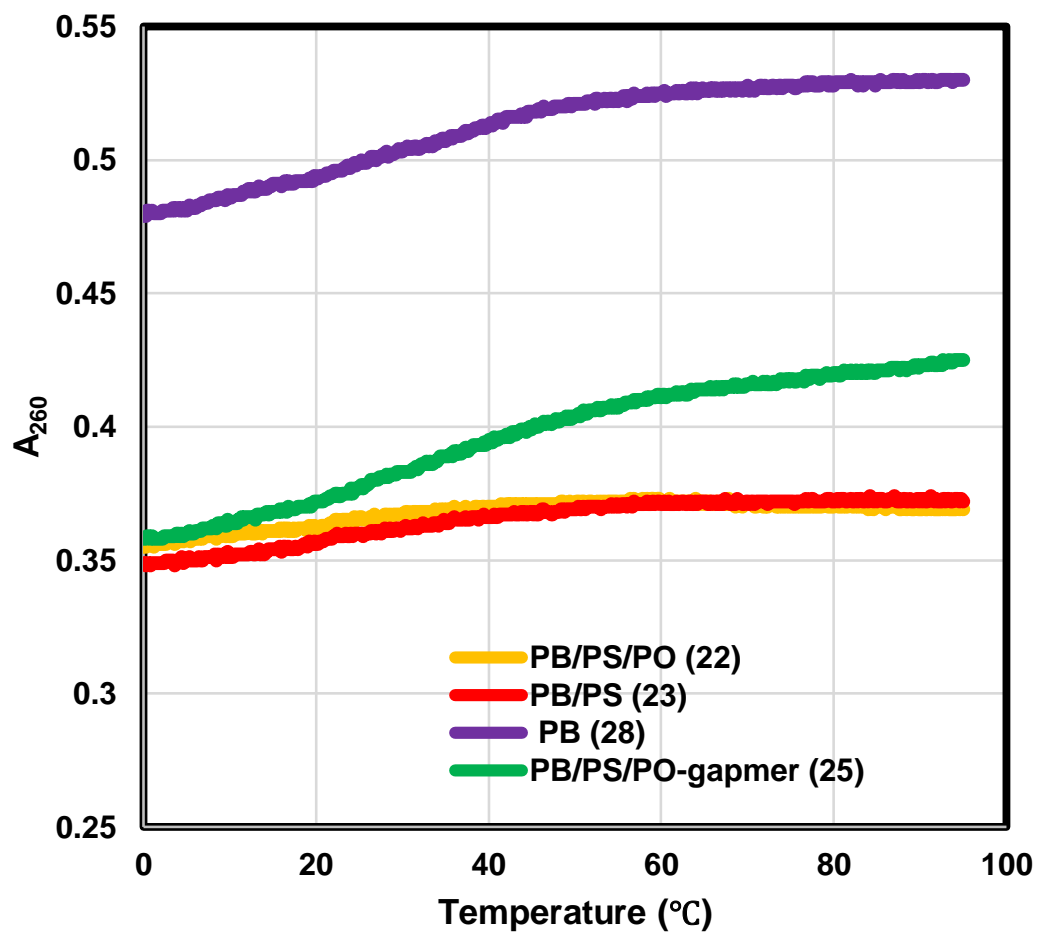

Figure S19. UV Melting curves of single stranded ODNs 22, 23, 25, and 28. 


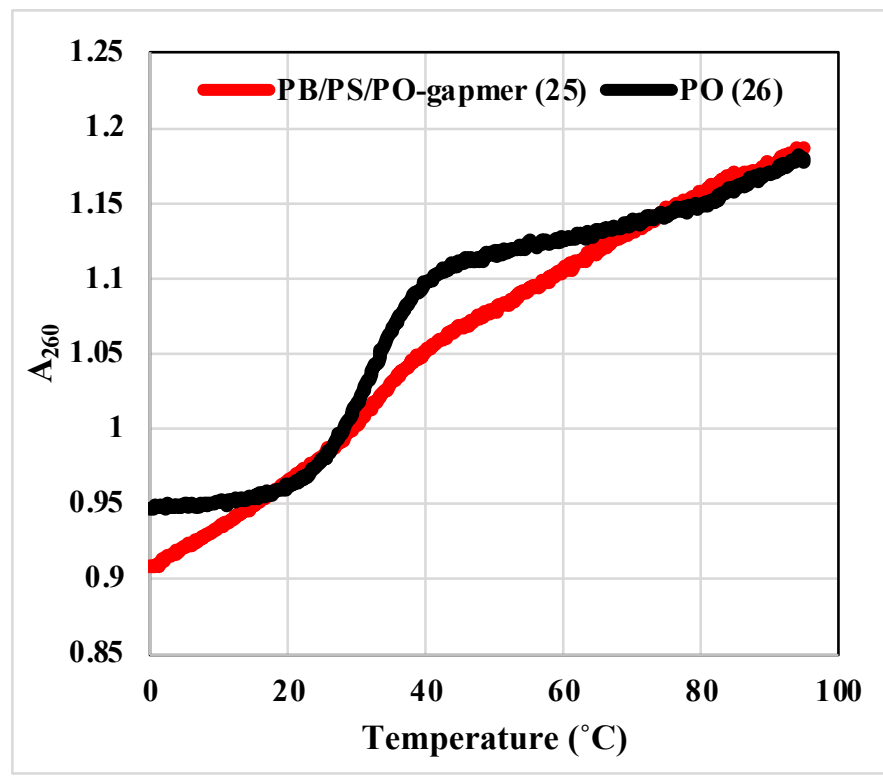

Figure S20. UV Melting curves of double stranded ODNs 25 and 26 with cRNA with a mismatched base. 
Nuclease resistance

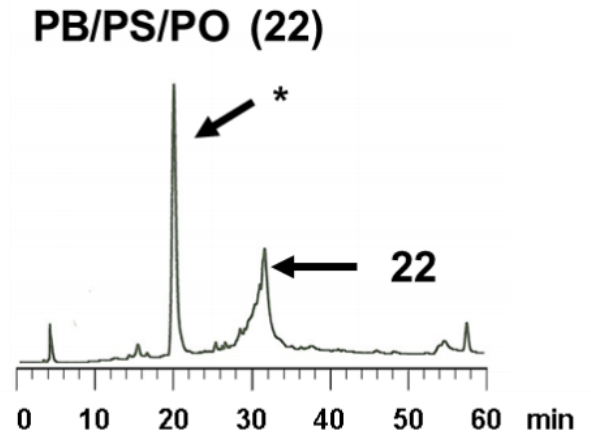

PB/PO (24)
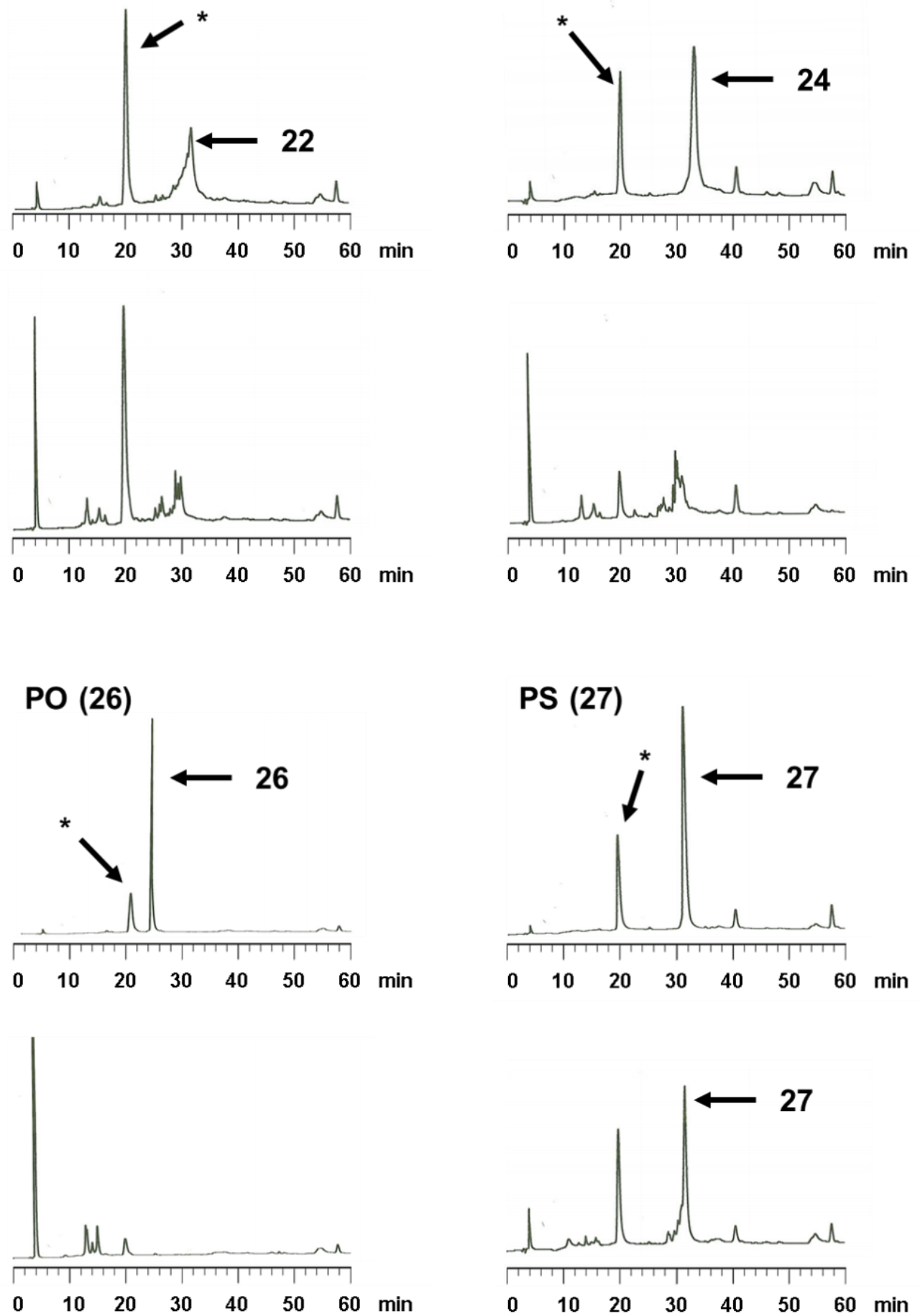

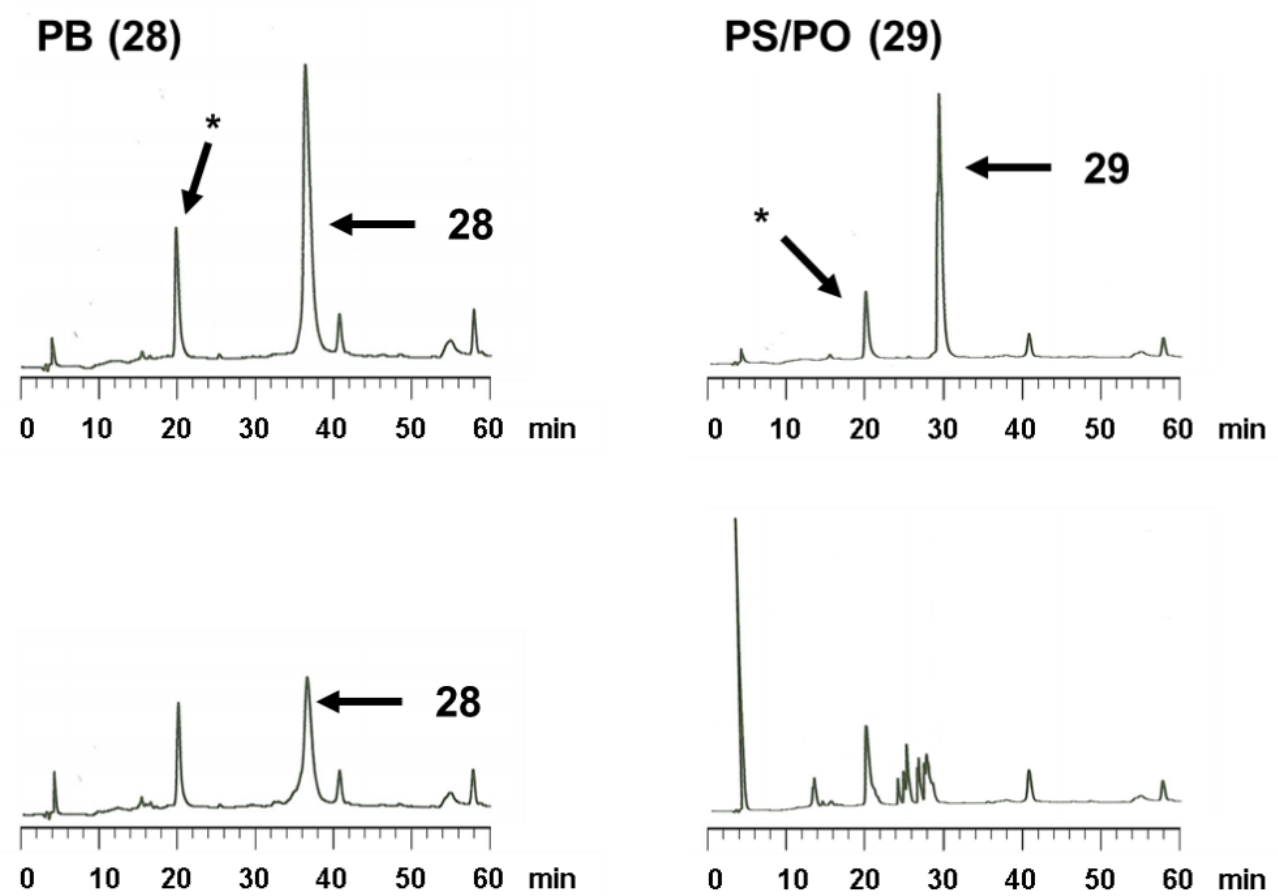

\section{Without DNA}

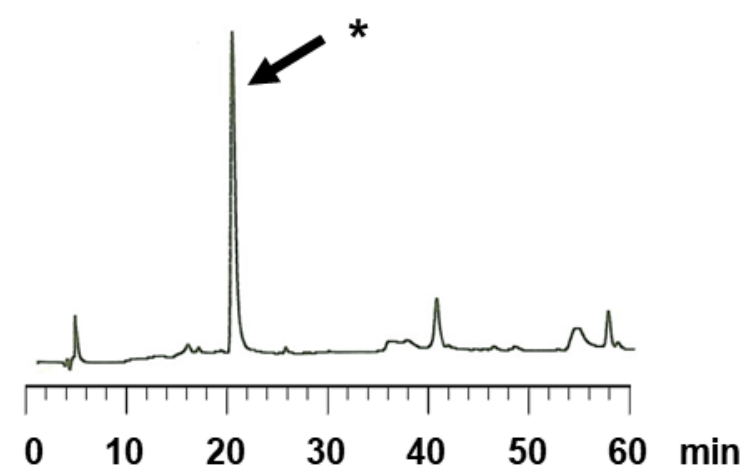

* indicates an artifact peak

Figure S21. RP-HPLC profiles of ODN before (upper) and after (lower) the treatment with snake venom phosphodiesterase (SVPDE) for $12 \mathrm{~h}$ at $37^{\circ} \mathrm{C}$. RP-HPLC was performed with a linear gradient of $0 \%-40 \%$ acetonitrile for $60 \mathrm{~min}$ in $0.1 \mathrm{M}$ triethylammonium acetate buffer $(\mathrm{pH} 7.0)$ at $30^{\circ} \mathrm{C}$ at a flow rate of 0.5 $\mathrm{mL} / \mathrm{min}$ using a $\mathrm{C} 18$ column 
RNase $H$ activity (25 U/mL)

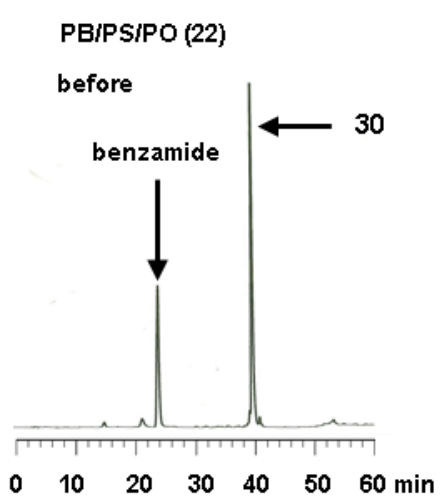

after

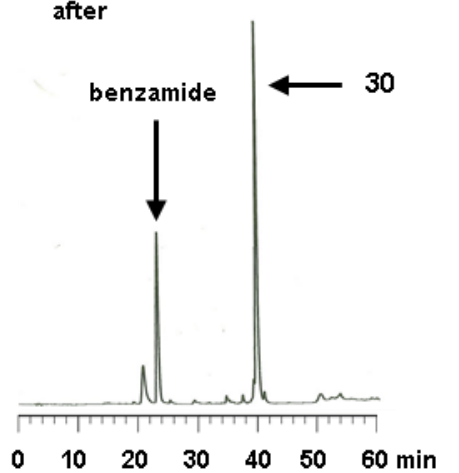

PBIPS (23)

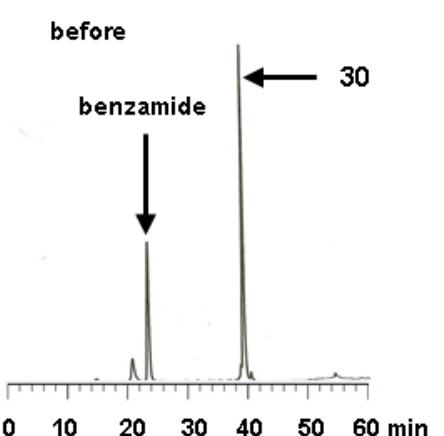

after

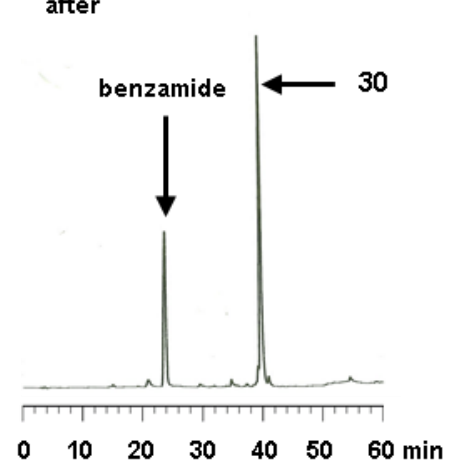

PBIPO (24)

before

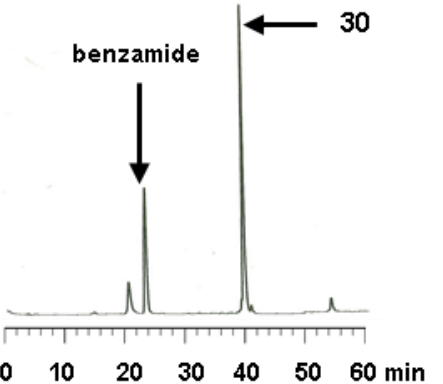

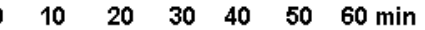

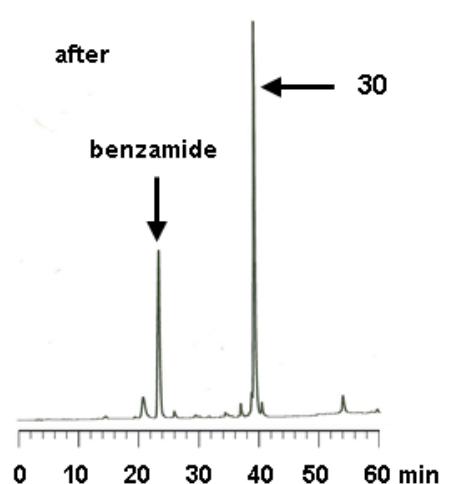

PBIPSIPO-gapmer(25)

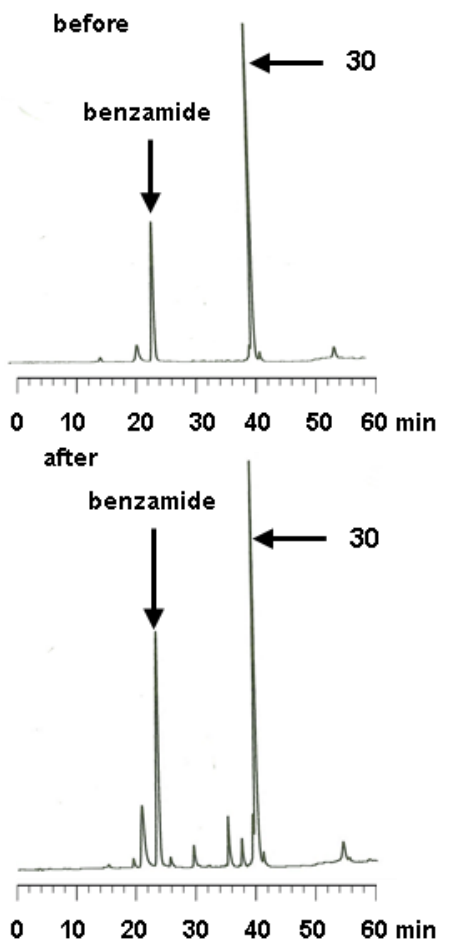



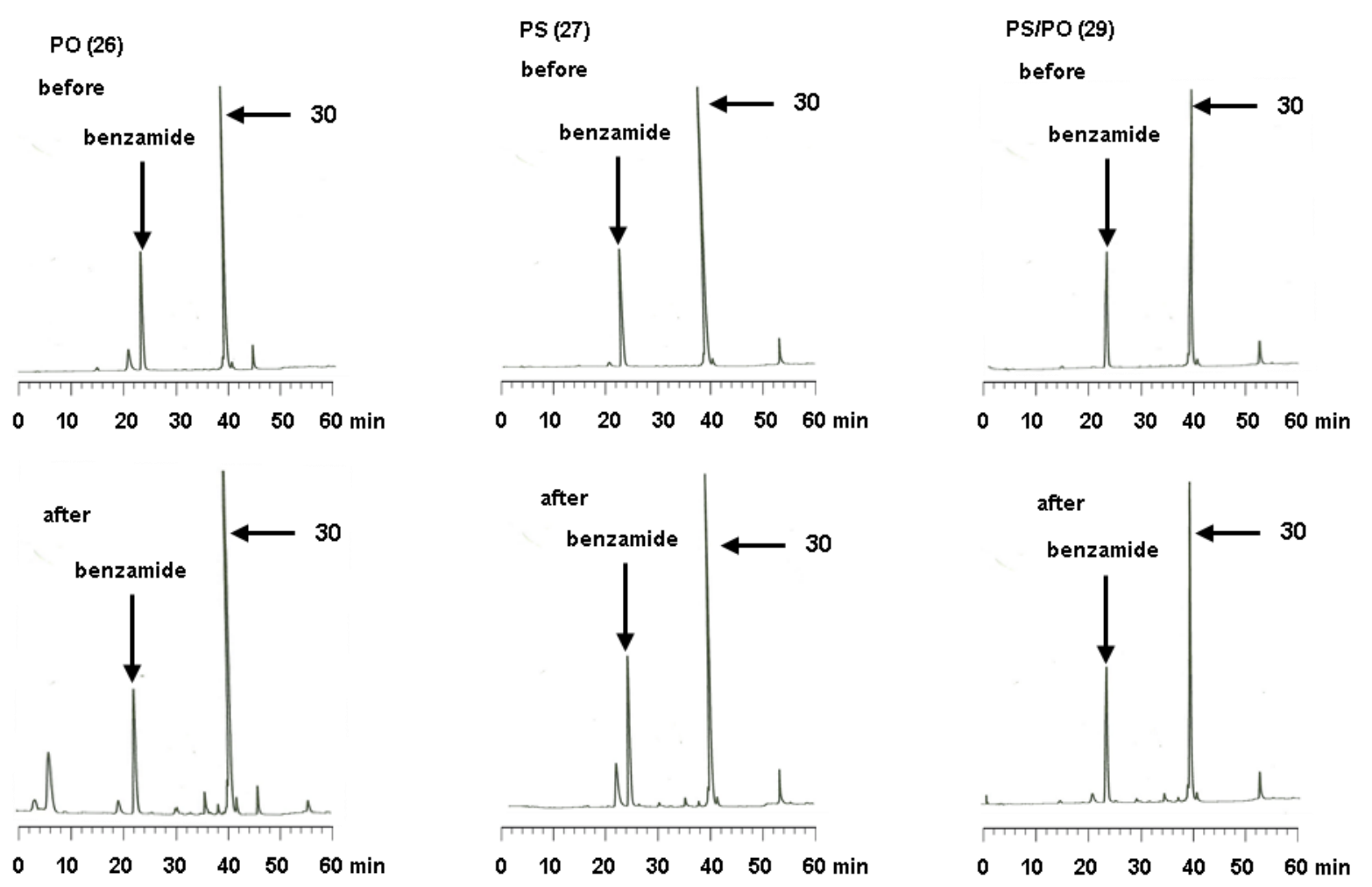

Figure S22. RP-HPLC profiles of ODN/cRNA duplexes before (upper) and after (lower) the treatment with $25 \mathrm{U} / \mathrm{mL}$ RNase $\mathrm{H}$ for 30 min at $37{ }^{\circ} \mathrm{C}$ RP-HPLC was performed with a linear gradient of $0 \%-11 \% \mathrm{MeCN}$ over $44 \mathrm{~min}$ followed by $11-40 \%$ over $16 \mathrm{~min}$ in $0.1 \mathrm{M}$ TEAA buffer (pH 7.0 ) at $50{ }^{\circ} \mathrm{C}$ with a flow rate of 0.5 $\mathrm{mL} / \mathrm{min}$. 
RNase $\mathrm{H}$ activity $(50 \mathrm{U} / \mathrm{mL})$

PBIPSIPO (22)
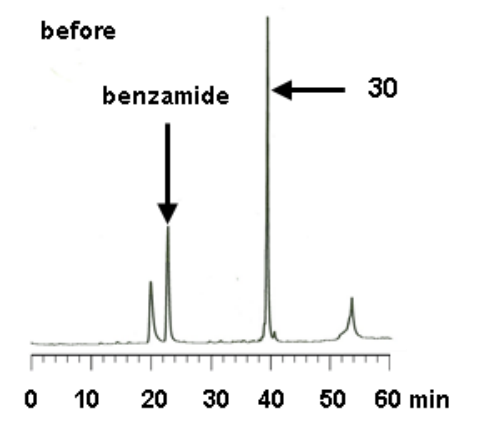

after

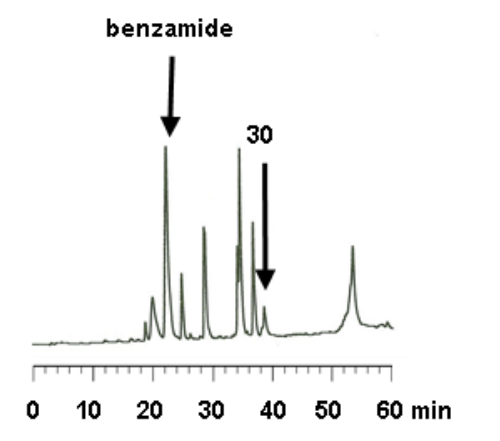

PBIPS (23)

before

benzamide
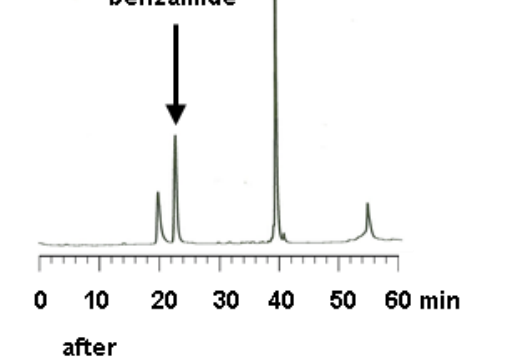

after

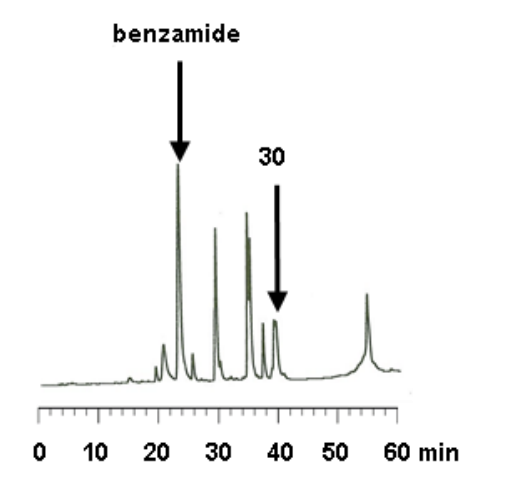

PBIPO (24)

before

benzamide
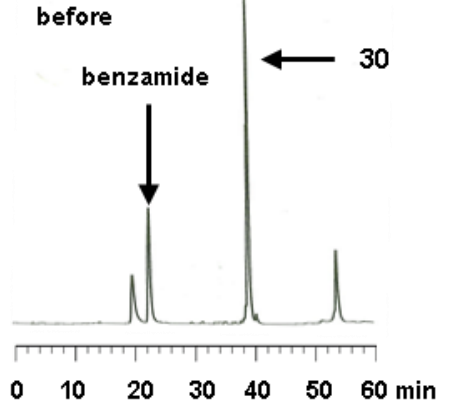

after

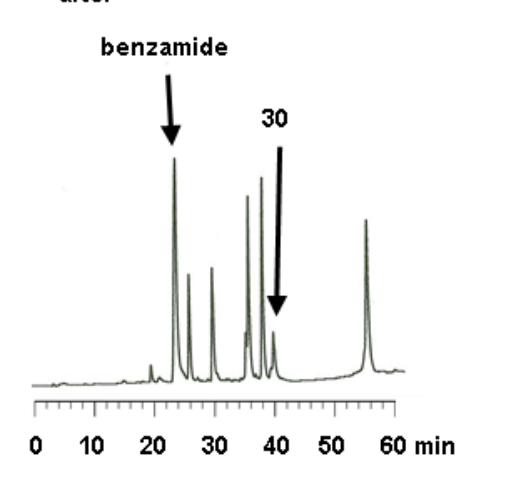

PS (27)
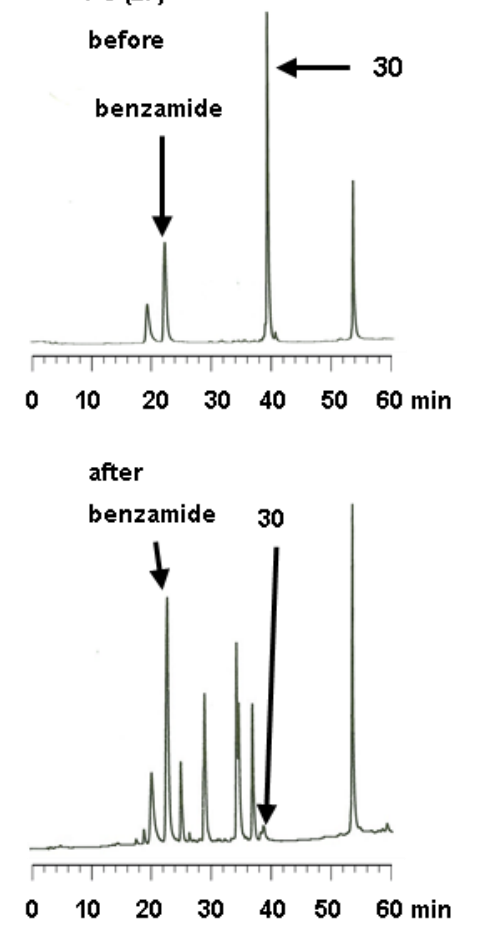

S25 


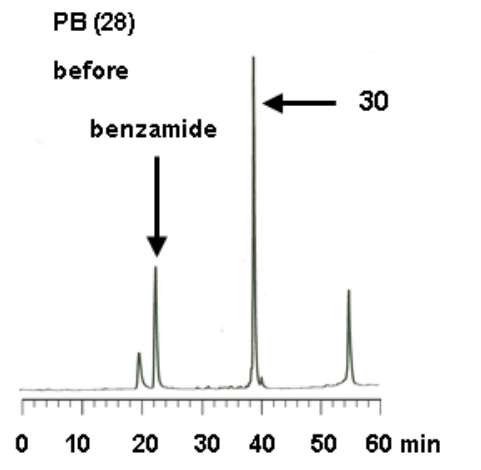

after

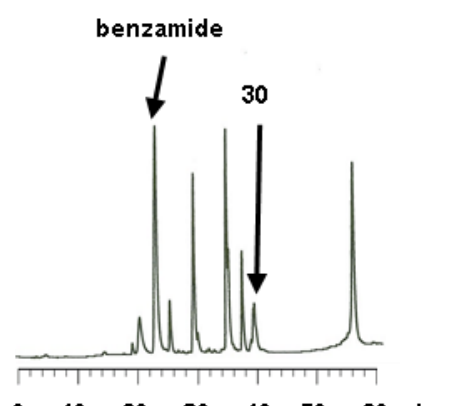

PSIPO (29)

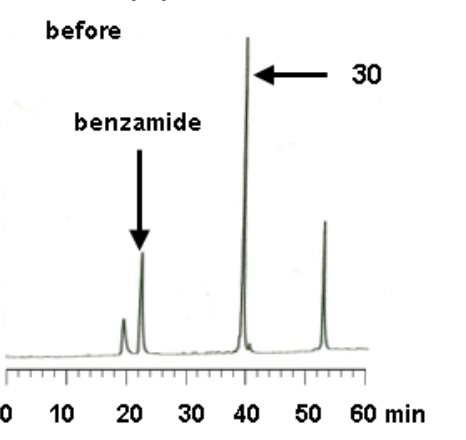

after

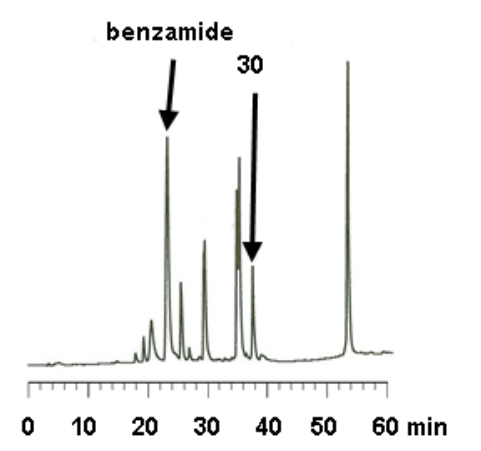

Figure S23. RP-HPLC profiles of ODN/cRNA duplexes before (upper) and after (lower) the treatment with $50 \mathrm{U} / \mathrm{mL} \mathrm{RNase} \mathrm{H}$ for $30 \mathrm{~min}$ at $37{ }^{\circ} \mathrm{C}$ RP-HPLC was performed with a linear gradient of $0 \%-11 \% \mathrm{MeCN}$ over $44 \mathrm{~min}$ followed by $11 \%-40 \%$ over 16 min in $0.1 \mathrm{M}$ TEAA buffer (pH 7.0 ) at $50{ }^{\circ} \mathrm{C}$ with a flow rate of 0.5 $\mathrm{mL} / \mathrm{min}$. 


\section{${ }^{1} \mathrm{H},{ }^{13} \mathrm{C},{ }^{31} \mathrm{P}$ NMR spectra}

\section{NMR spectra}

${ }^{1} \mathrm{H}-\mathrm{NMR}\left(400 \mathrm{MHz}, \mathrm{CDCl}_{3}\right.$ )

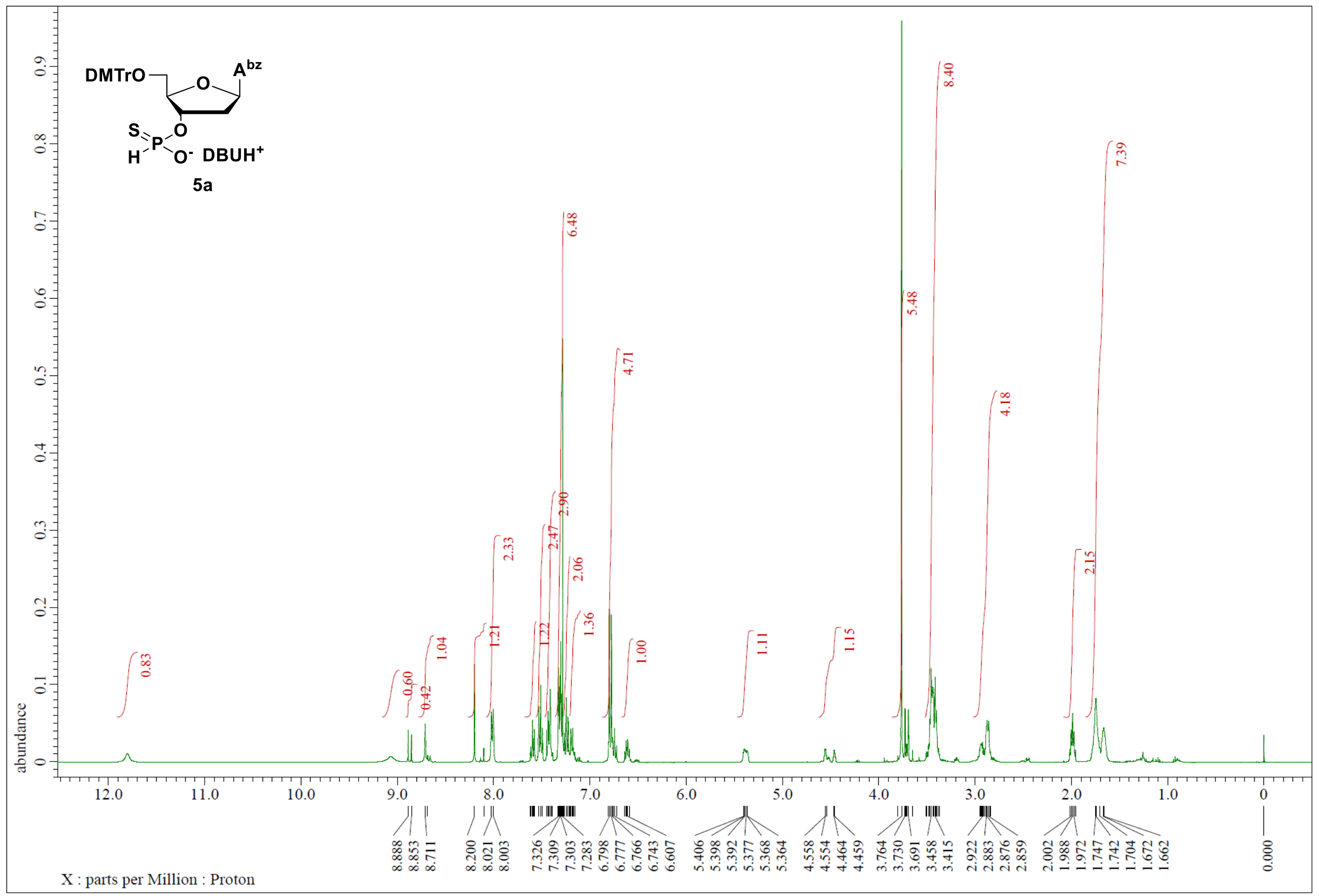


${ }^{13} \mathrm{C}\{\mathrm{H}\} \mathrm{NMR}\left(100 \mathrm{MHz}, \mathrm{CDCl}_{3}\right)$

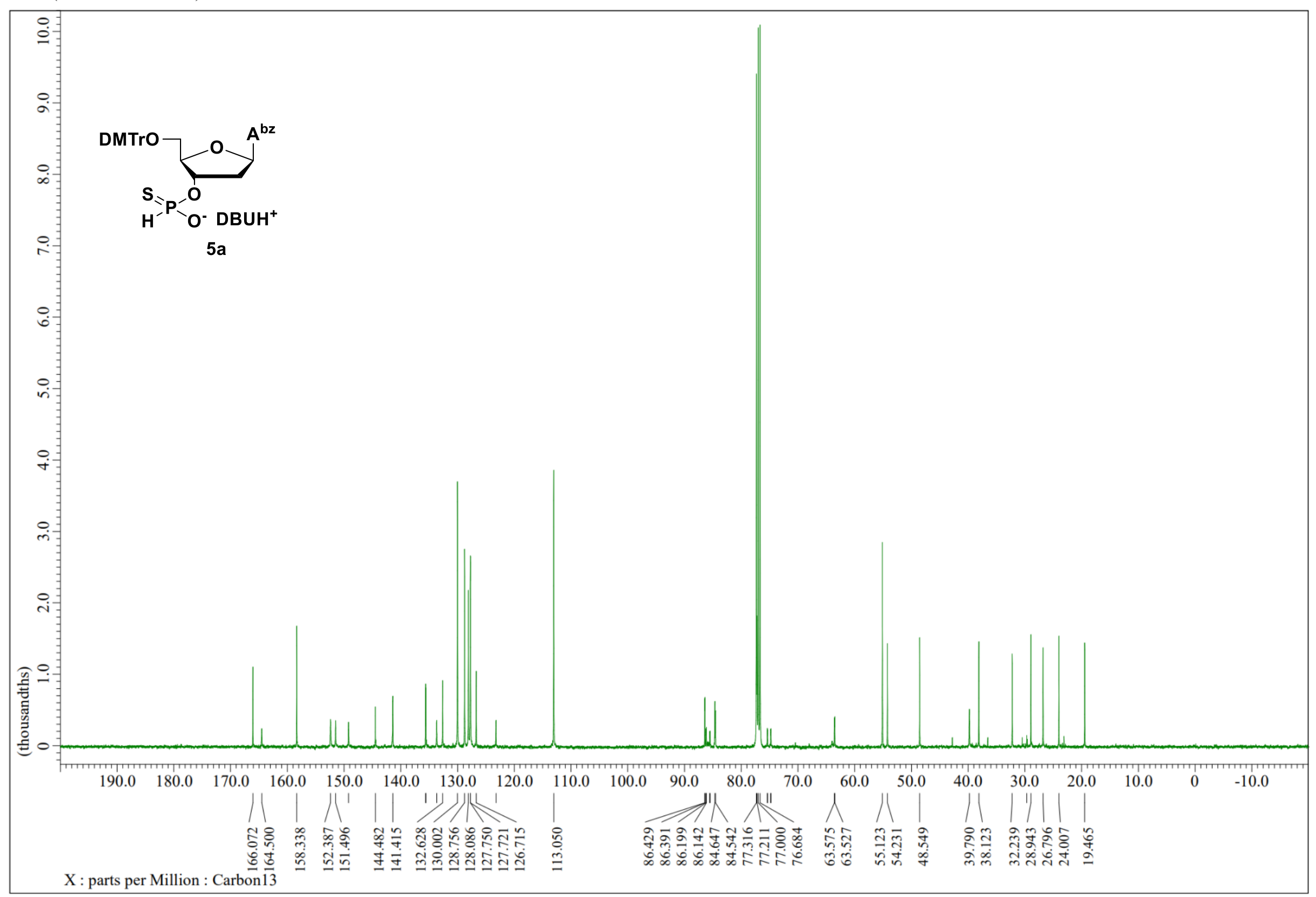


${ }^{31} \mathrm{P}\left\{{ }^{1} \mathrm{H}\right\}$ NMR $\left(162 \mathrm{MHz}, \mathrm{CDCl}_{3}\right)$

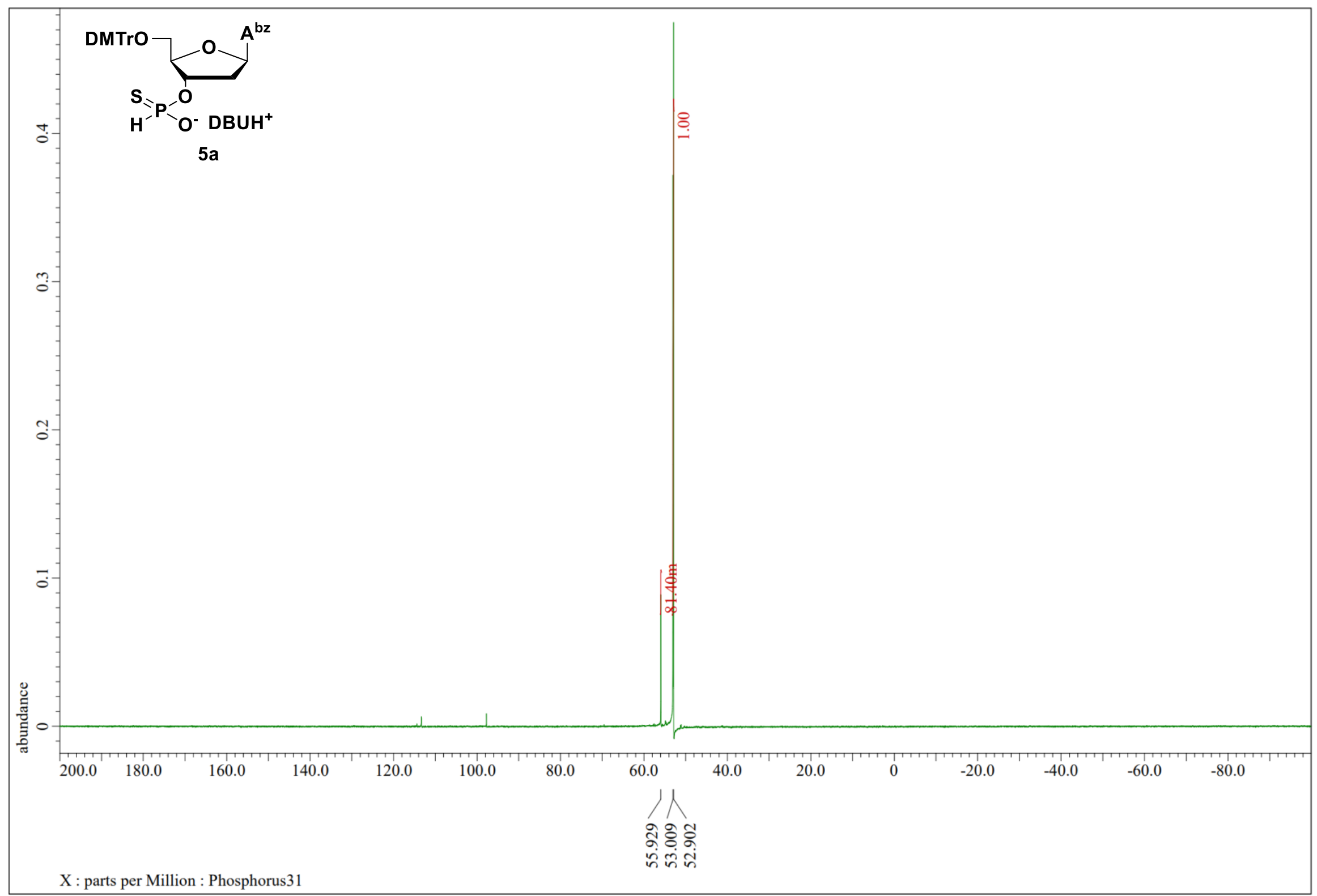


${ }^{1} \mathrm{H}-\mathrm{NMR}\left(400 \mathrm{MHz}, \mathrm{CDCl}_{3}\right.$ )

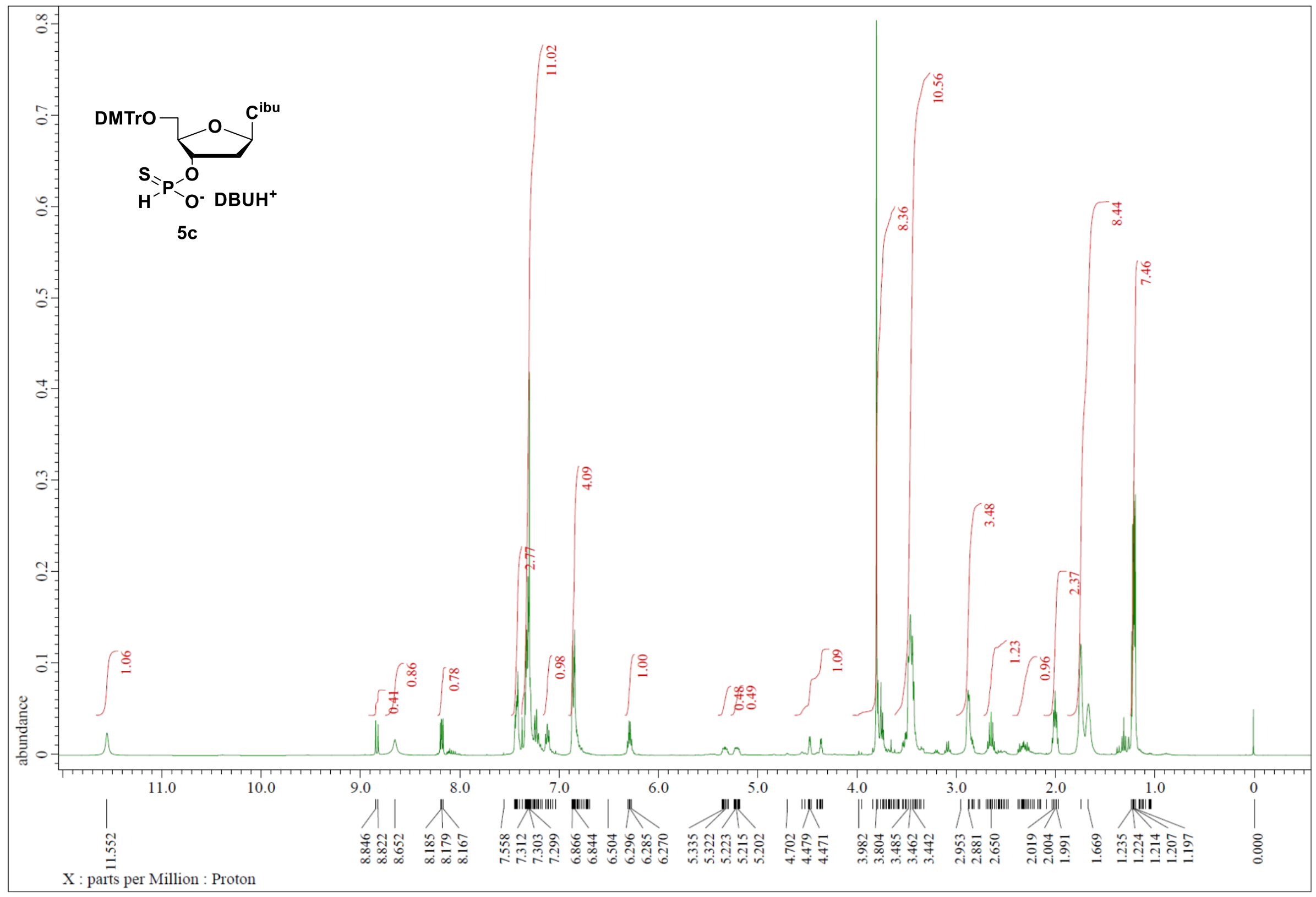


${ }^{13} \mathrm{C}\left\{{ }^{1} \mathrm{H}\right\}$ NMR $\left(100 \mathrm{MHz}, \mathrm{CDCl}_{3}\right)$

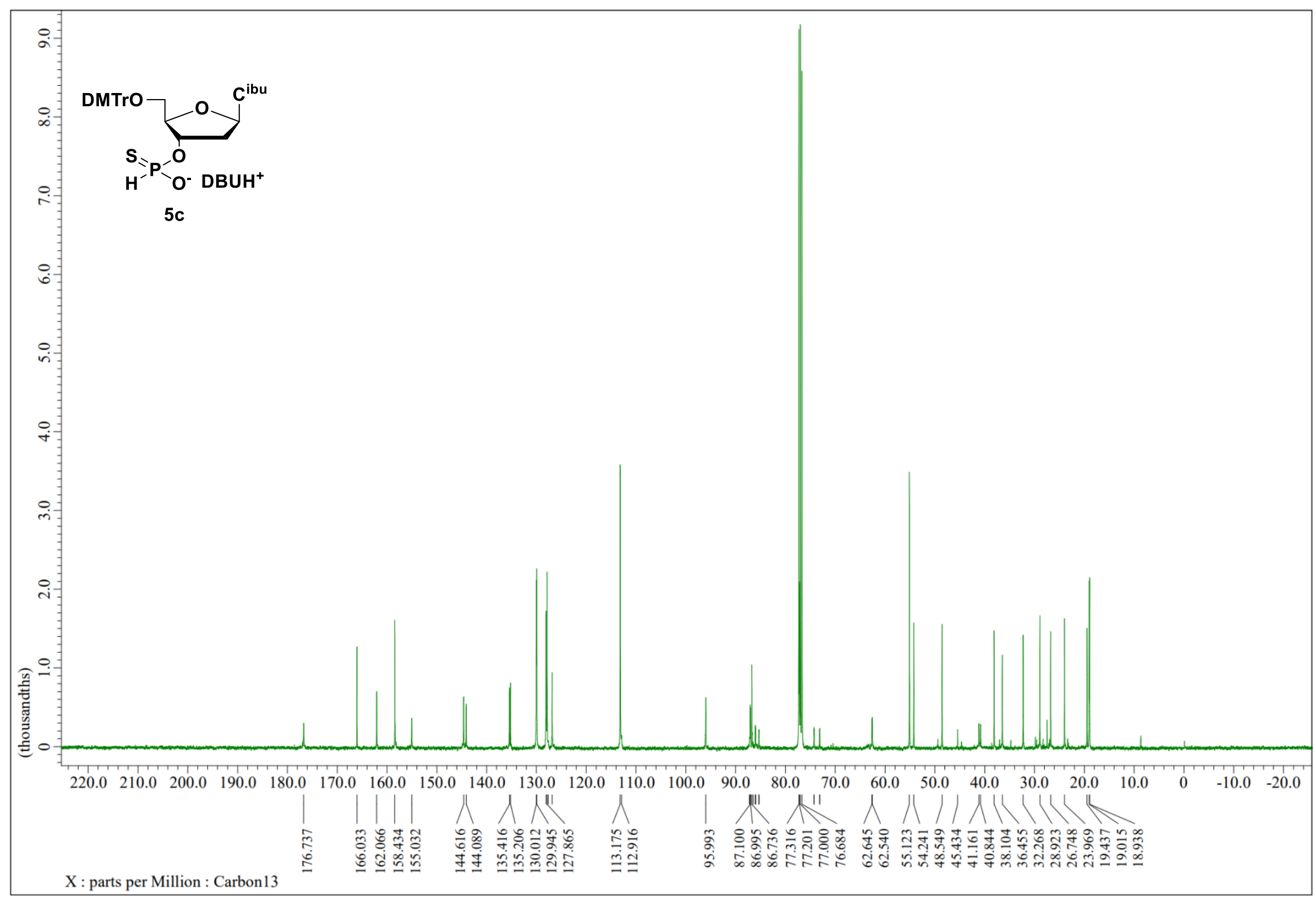


${ }^{31} \mathrm{P}\left\{{ }^{1} \mathrm{H}\right\}$ NMR $\left(162 \mathrm{MHz}, \mathrm{CDCl}_{3}\right)$

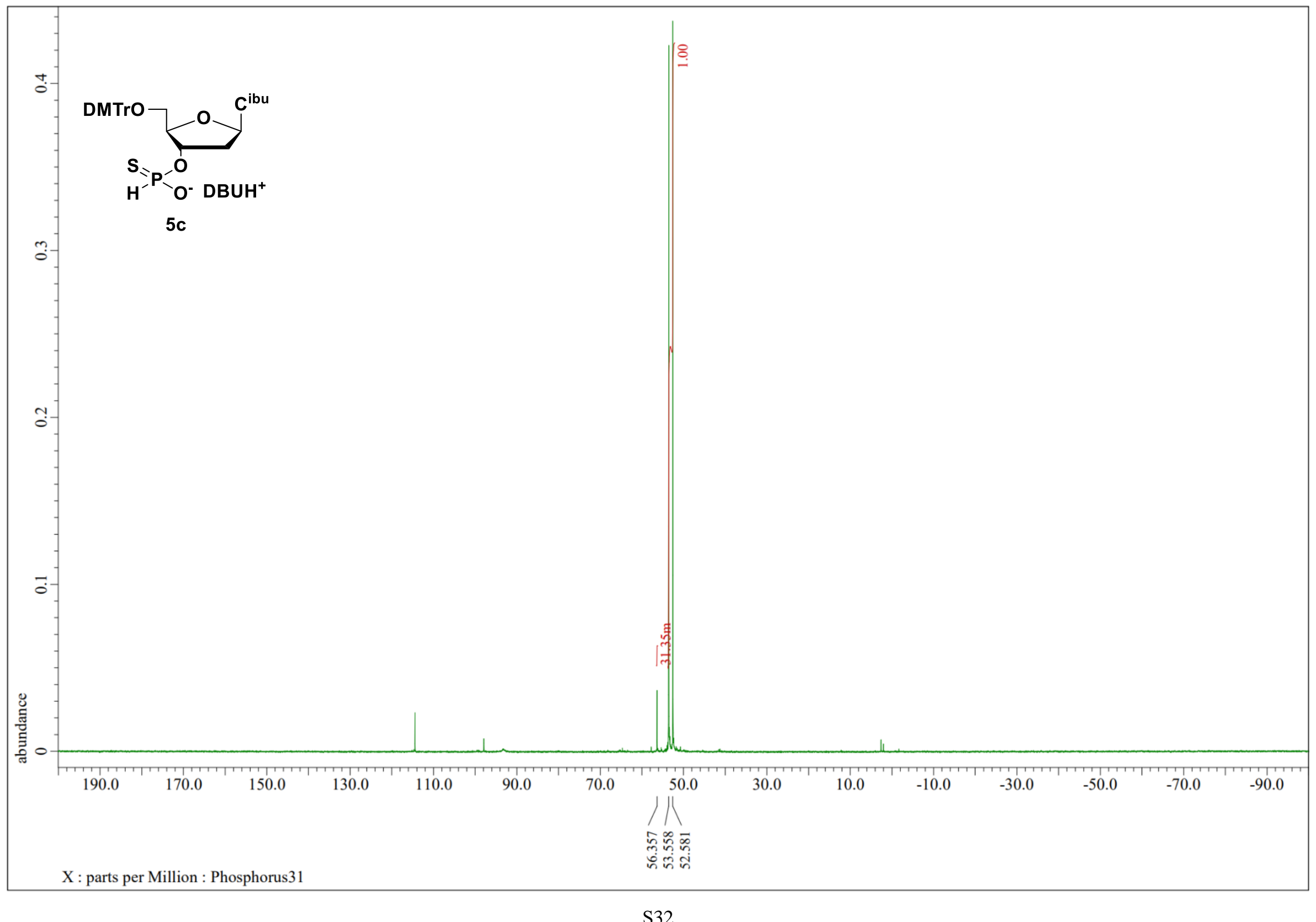




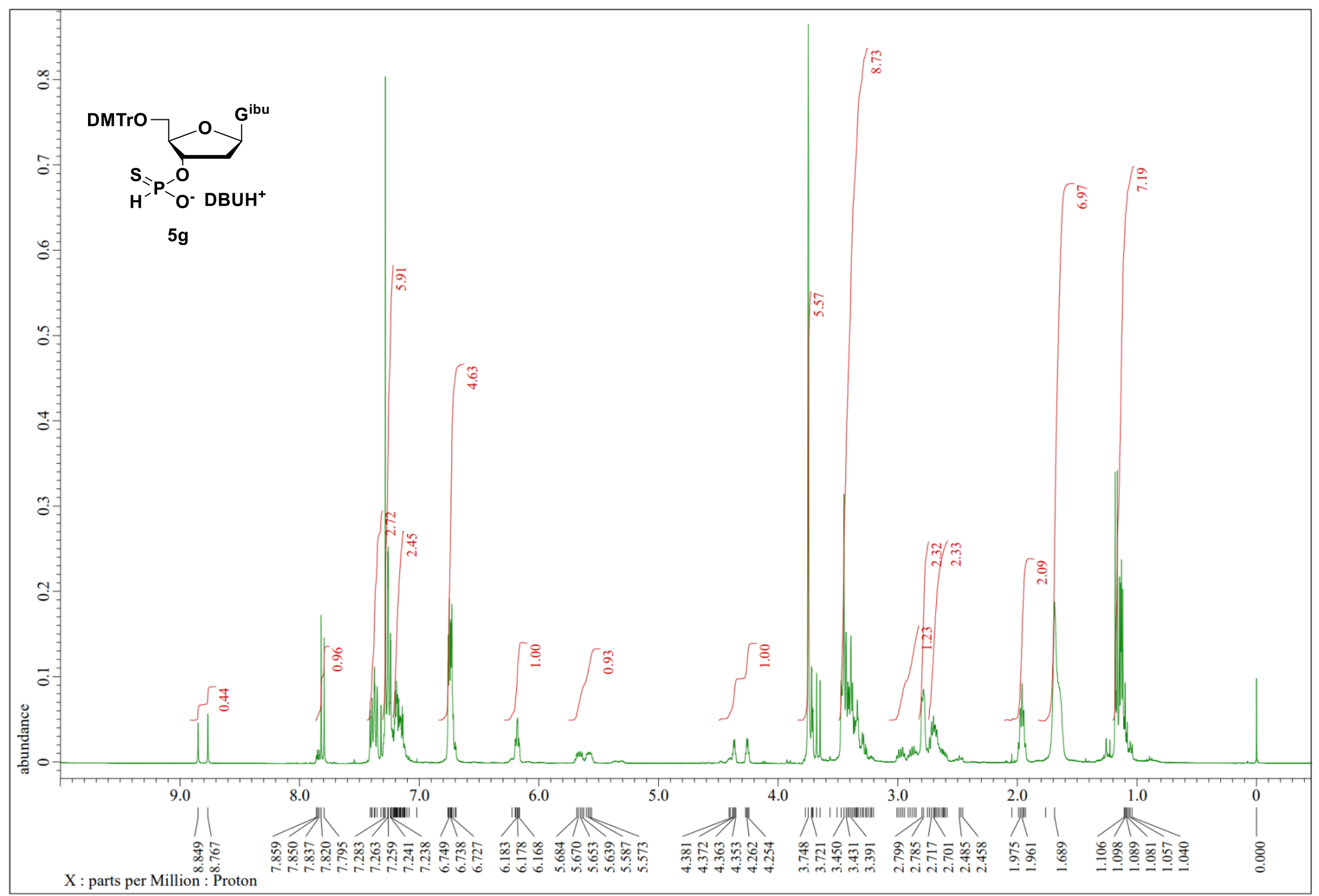


${ }^{13} \mathrm{C}\{\mathrm{H}\} \mathrm{NMR}\left(100 \mathrm{MHz}, \mathrm{CDCl}_{3}\right)$

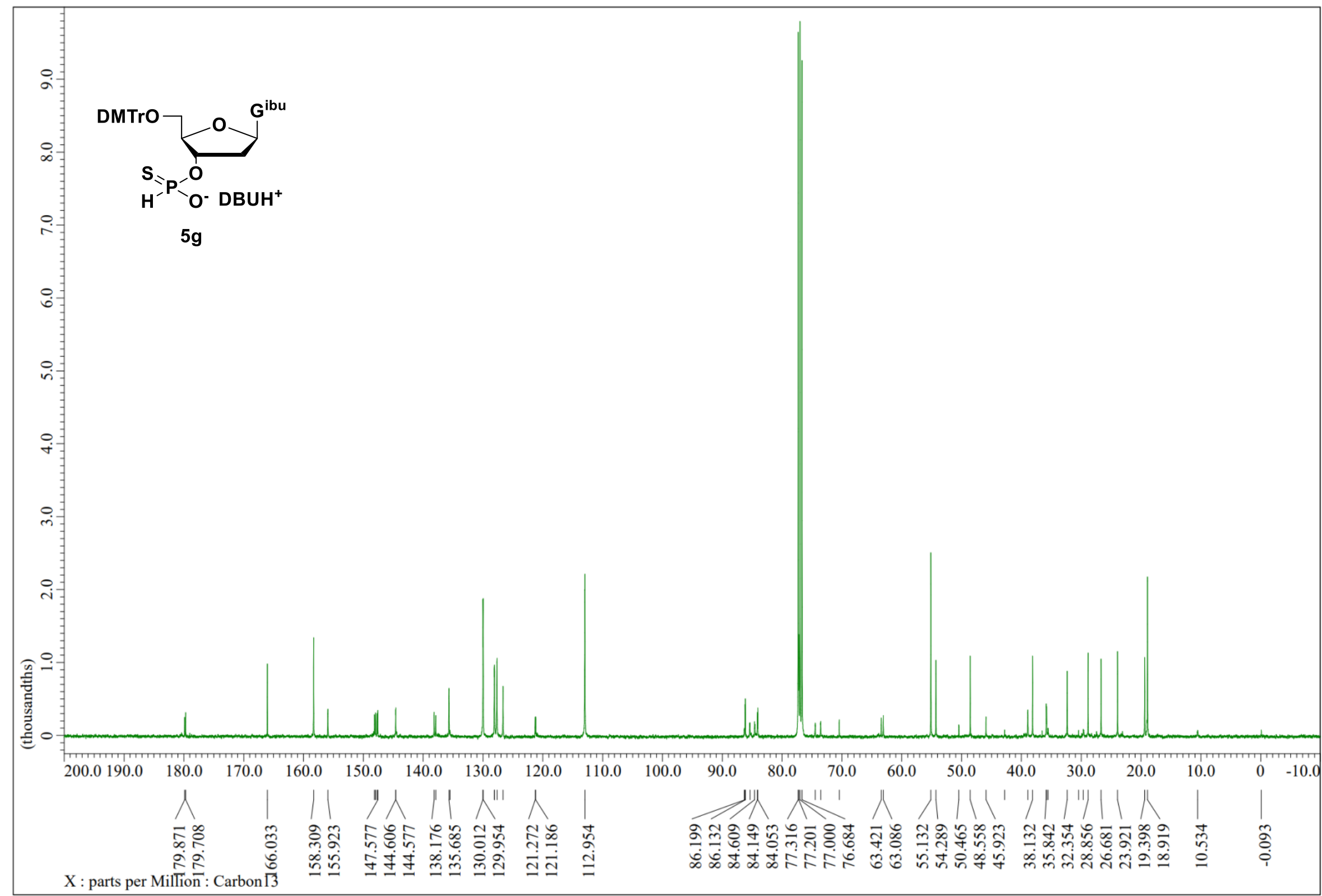


${ }^{31} \mathrm{P}\left\{{ }^{1} \mathrm{H}\right\}$ NMR (162 MHz, $\left.\mathrm{CDCl}_{3}\right)$

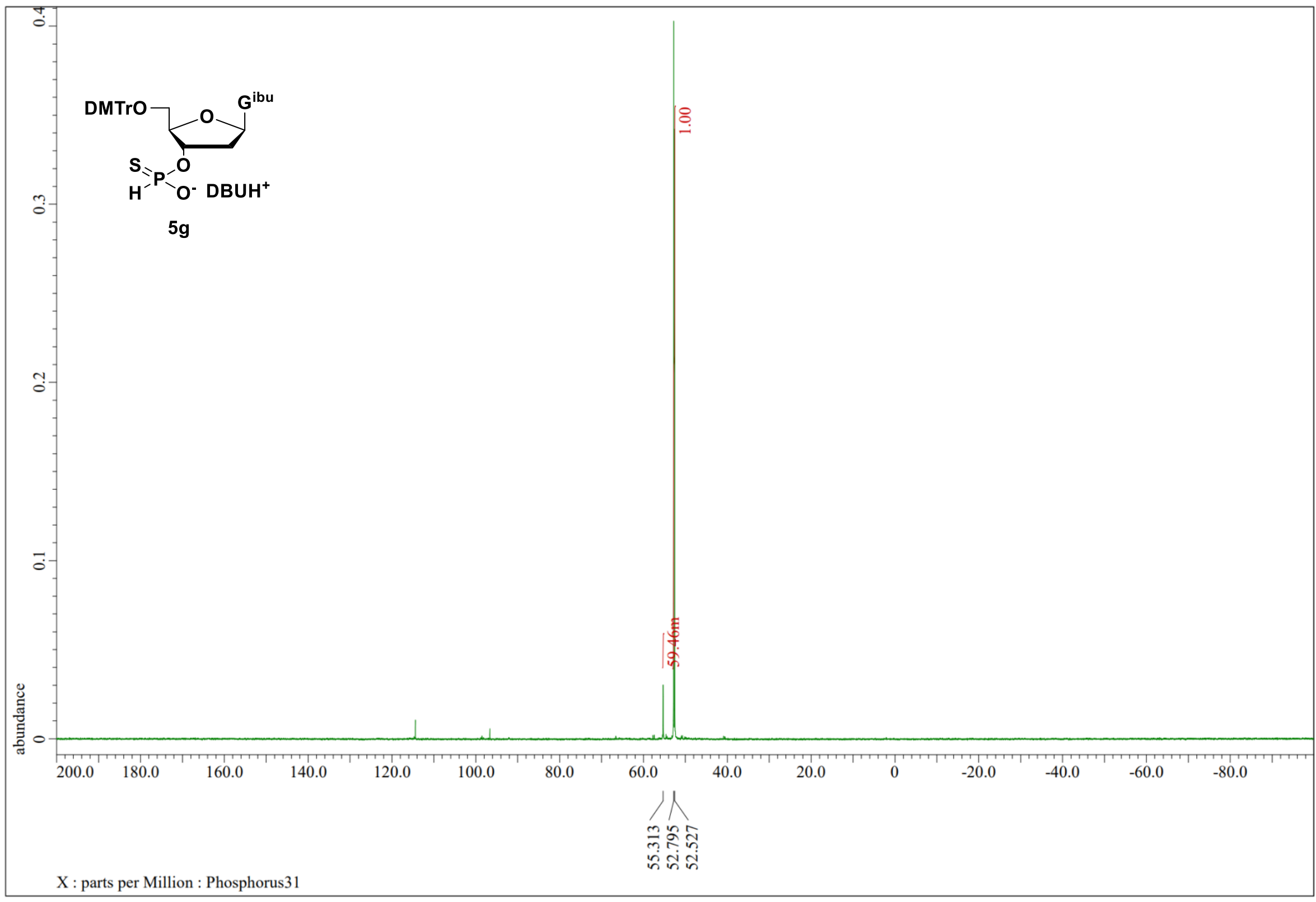


${ }^{1} \mathrm{H}-\mathrm{NMR}\left(400 \mathrm{MHz}, \mathrm{CDCl}_{3}\right.$ )

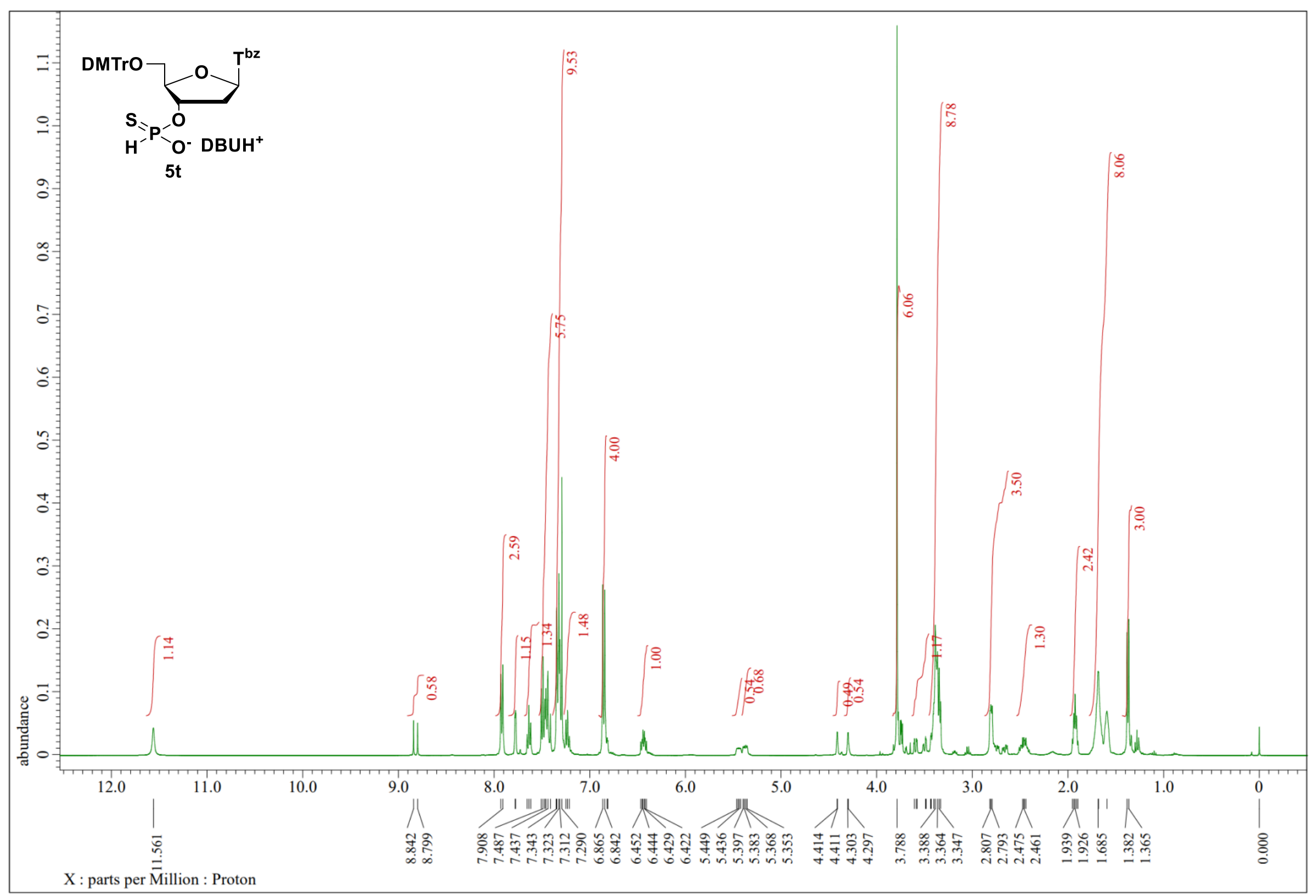


${ }^{13} \mathrm{C}\{\mathrm{H}\}$ NMR $\left(100 \mathrm{MHz}, \mathrm{CDCl}_{3}\right)$

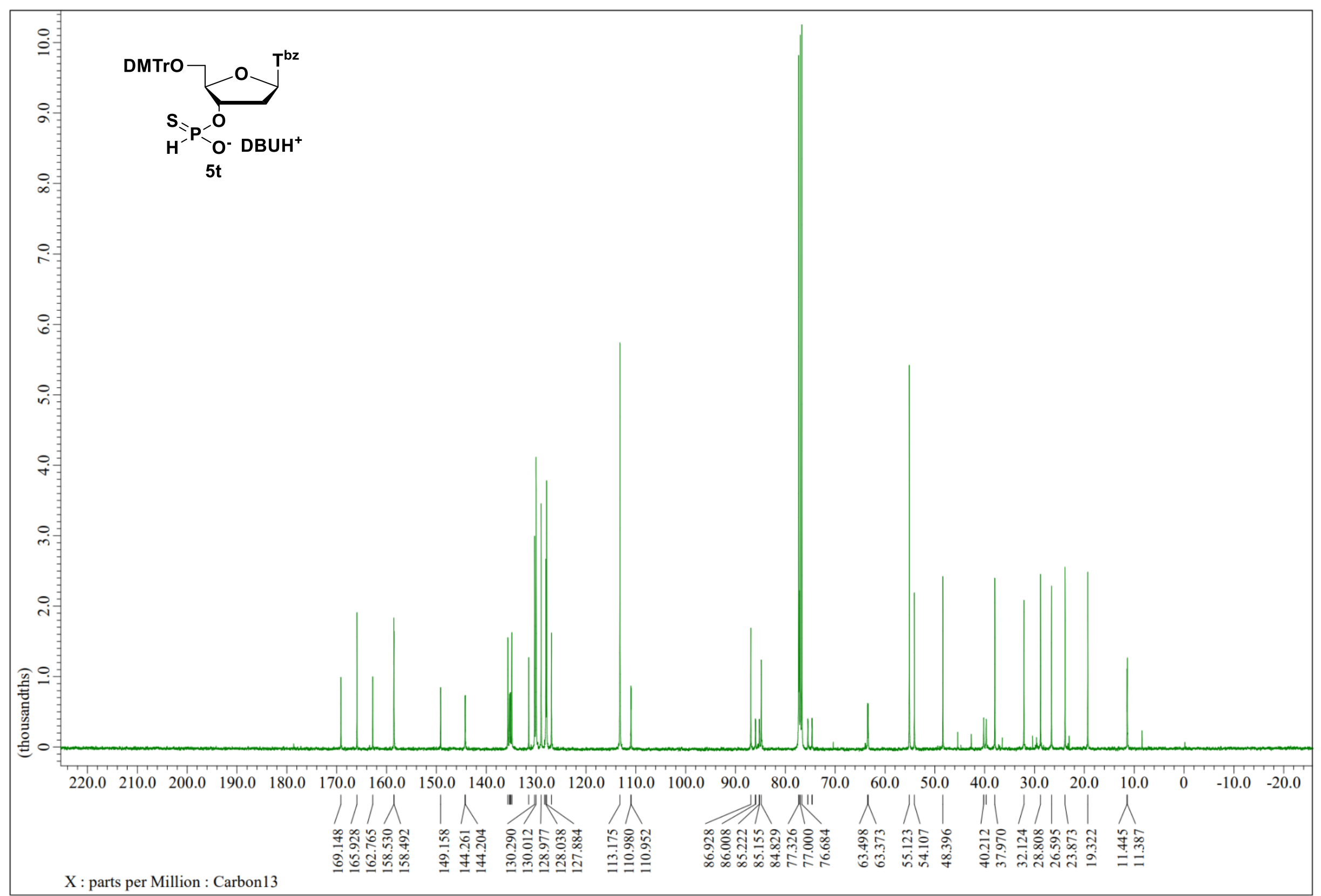


${ }^{31} \mathrm{P}\left\{{ }^{1} \mathrm{H}\right\} \mathrm{NMR}\left(162 \mathrm{MHz}, \mathrm{CDCl}_{3}\right)$

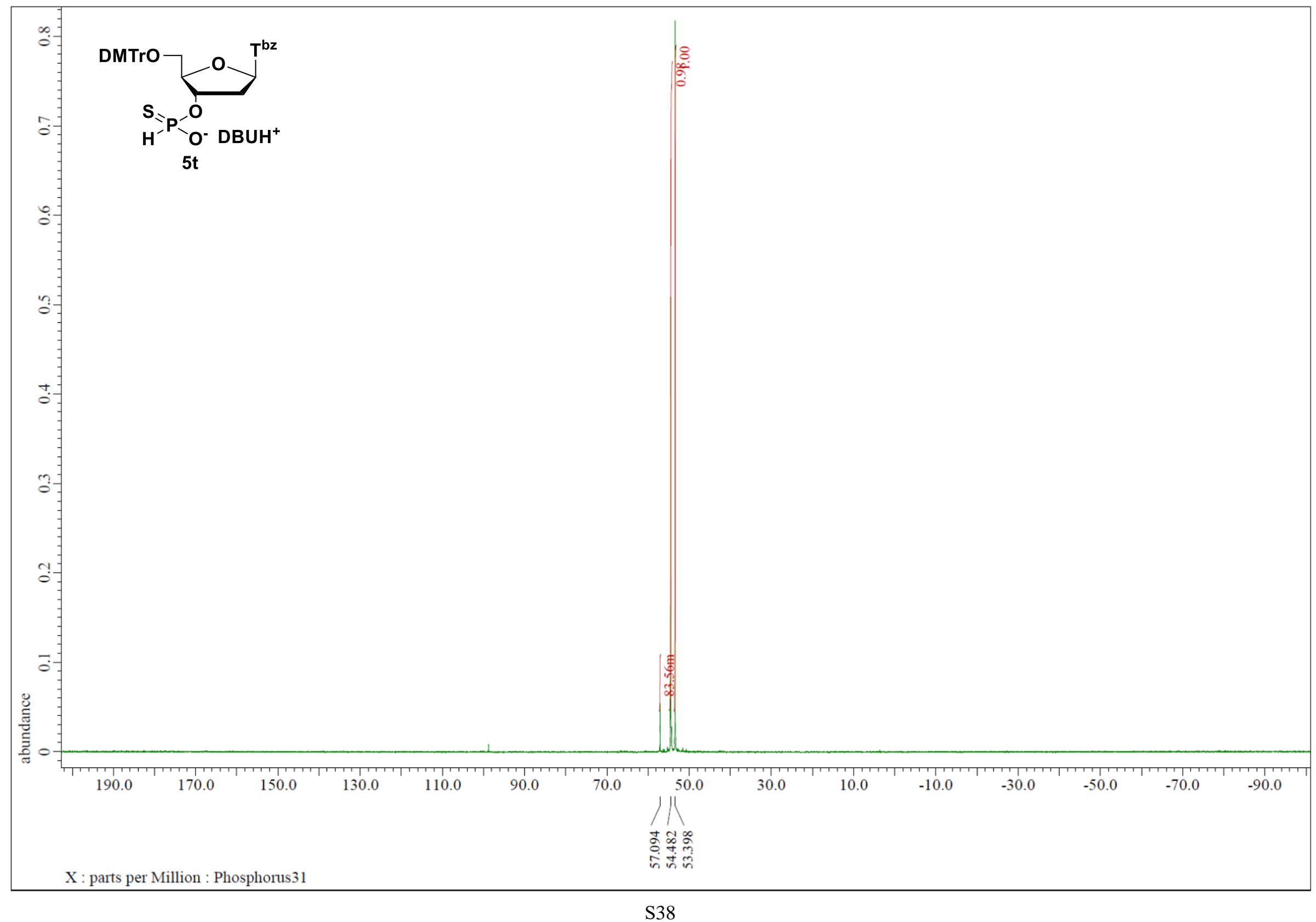


${ }^{1} \mathrm{H}-\mathrm{NMR}\left(400 \mathrm{MHz}, \mathrm{CDCl}_{3}\right.$ )

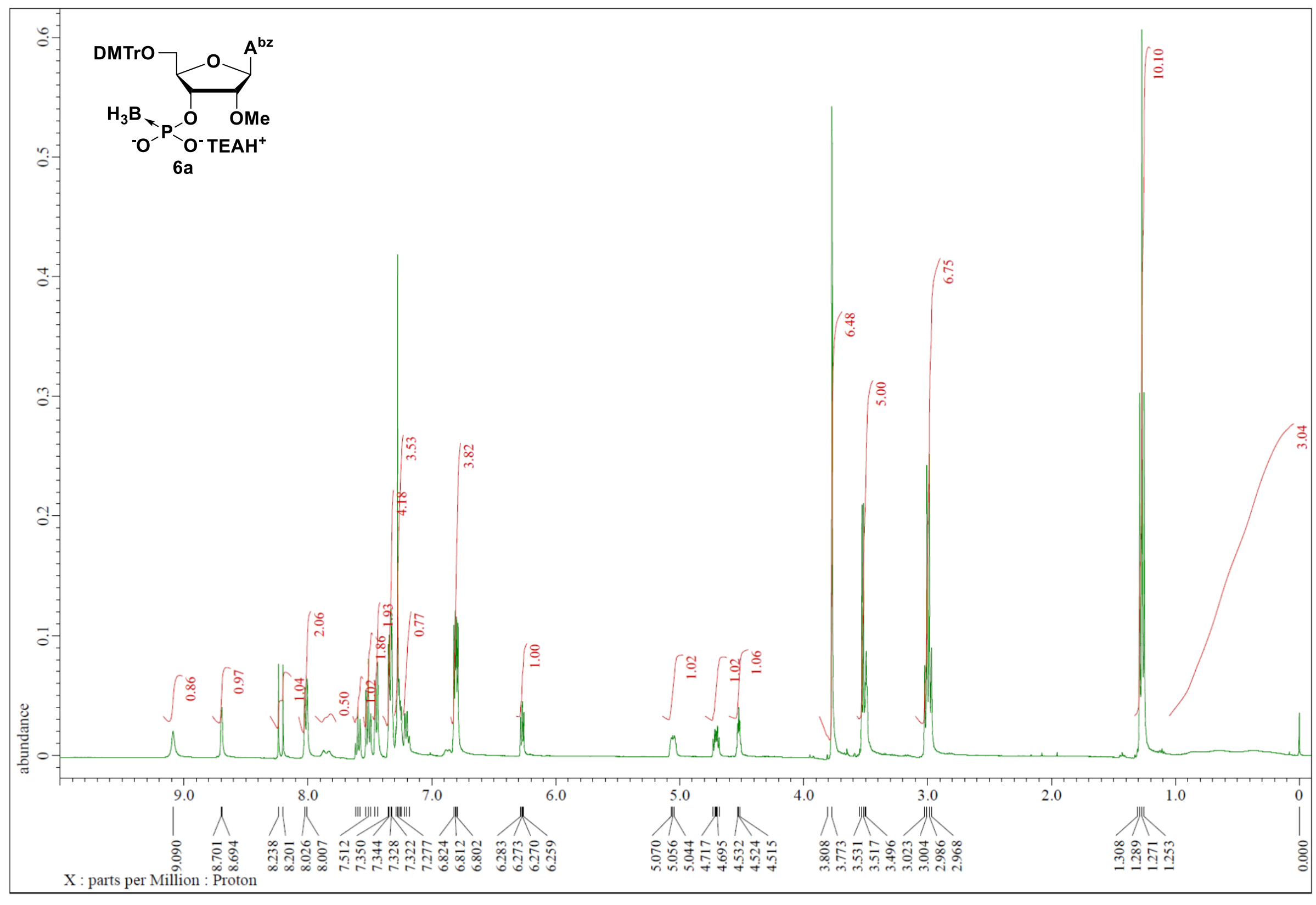


${ }^{13} \mathrm{C}\{\mathrm{H}\}$ NMR $\left(100 \mathrm{MHz}, \mathrm{CDCl}_{3}\right)$

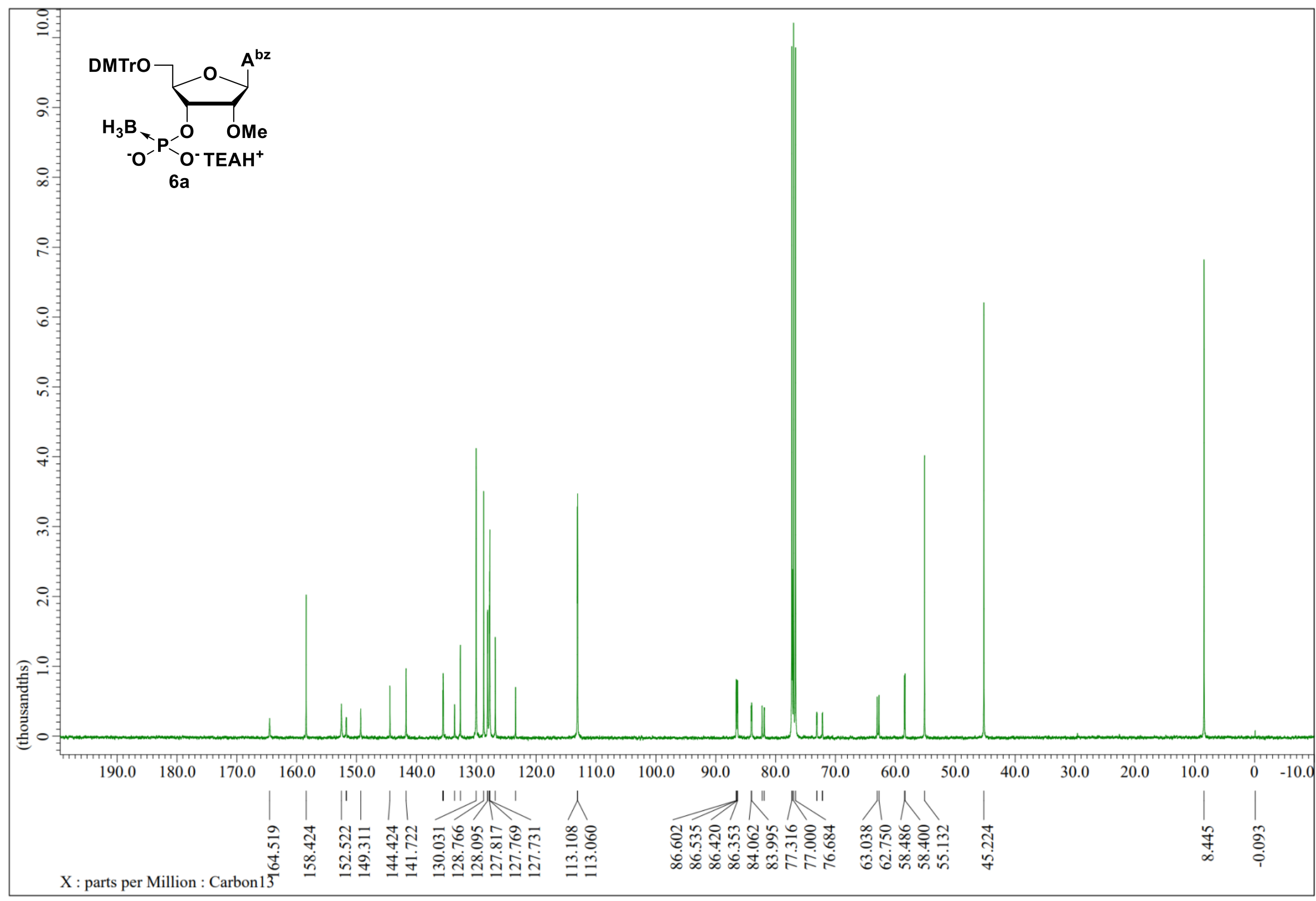


${ }^{31} \mathrm{P}\left\{{ }^{1} \mathrm{H}\right\}$ NMR (162 MHz, $\left.\mathrm{CDCl}_{3}\right)$

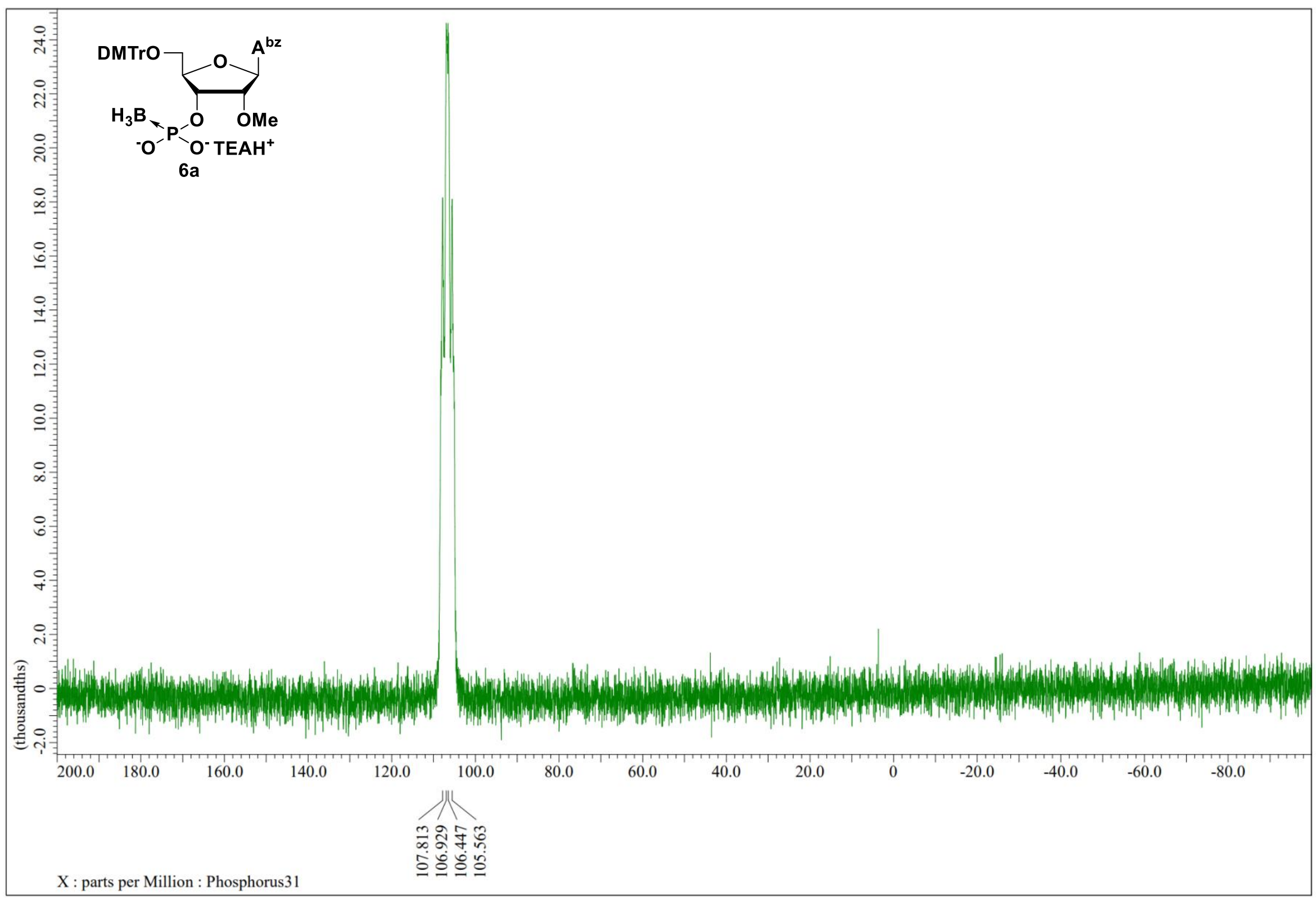


${ }^{1} \mathrm{H}-\mathrm{NMR}\left(400 \mathrm{MHz}, \mathrm{CDCl}_{3}\right)$

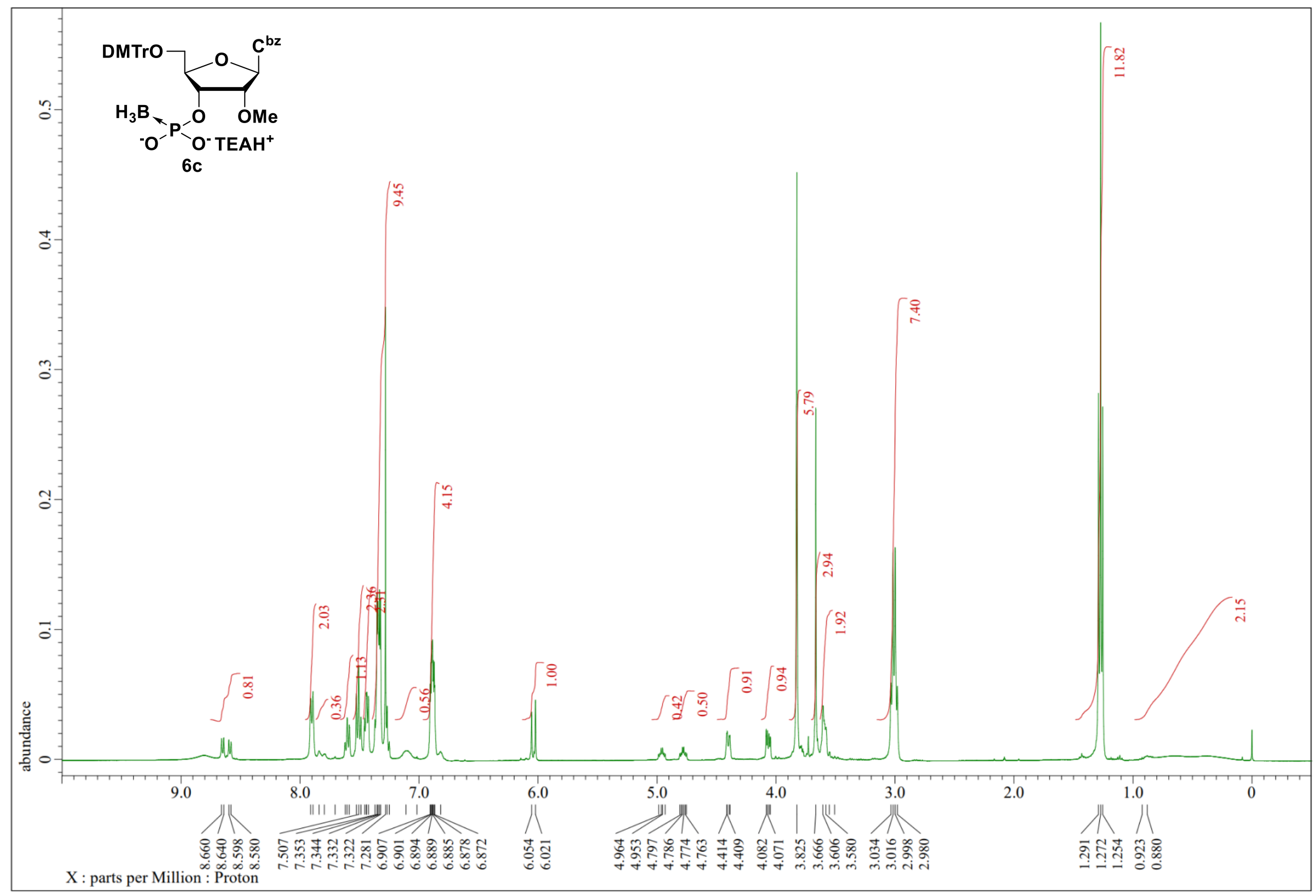


${ }^{13} \mathrm{C}\{\mathrm{H}\} \mathrm{NMR}\left(100 \mathrm{MHz}, \mathrm{CDCl}_{3}\right)$

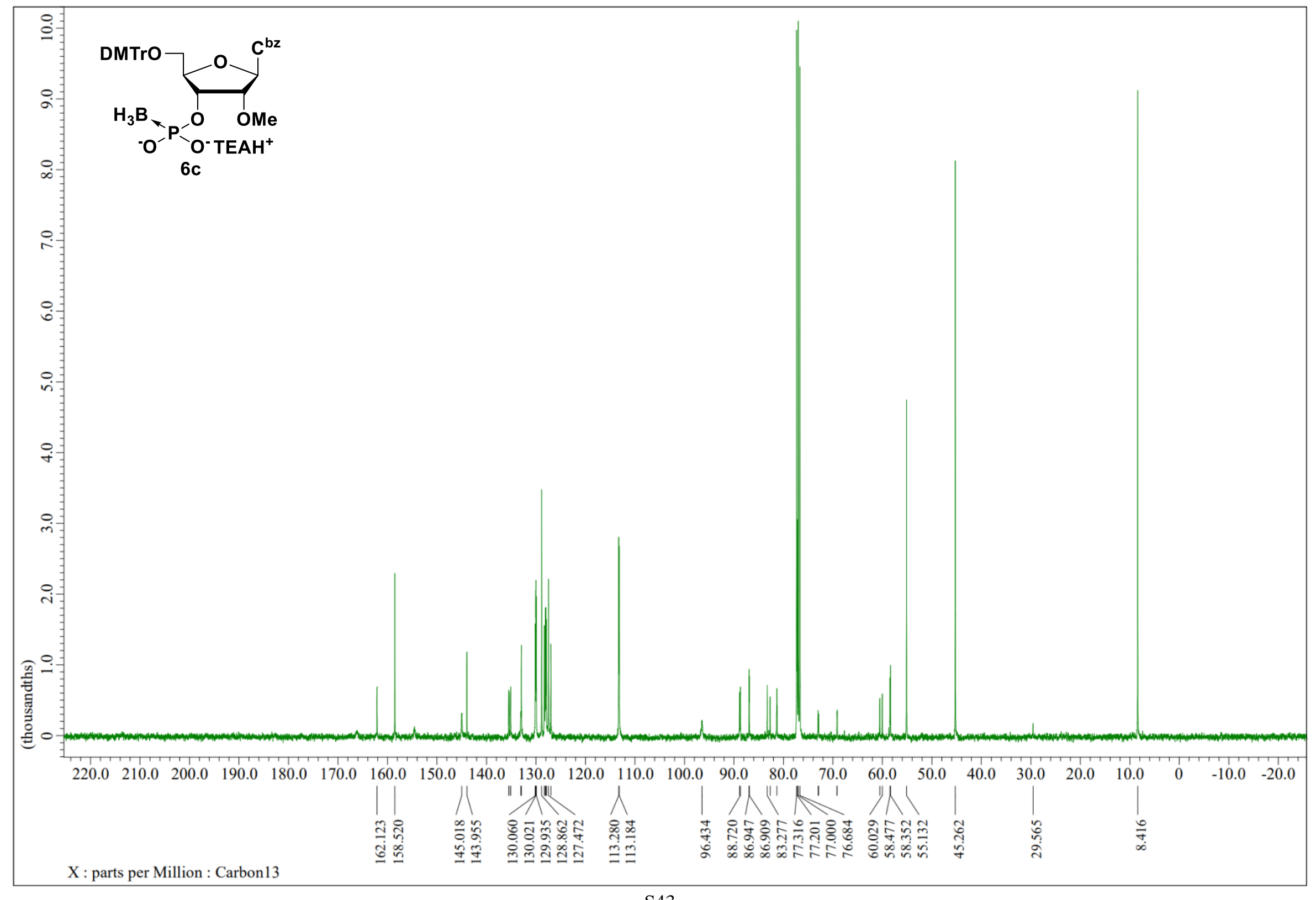


${ }^{31} \mathrm{P}\left\{{ }^{1} \mathrm{H}\right\}$ NMR $\left(162 \mathrm{MHz}, \mathrm{CDCl}_{3}\right)$

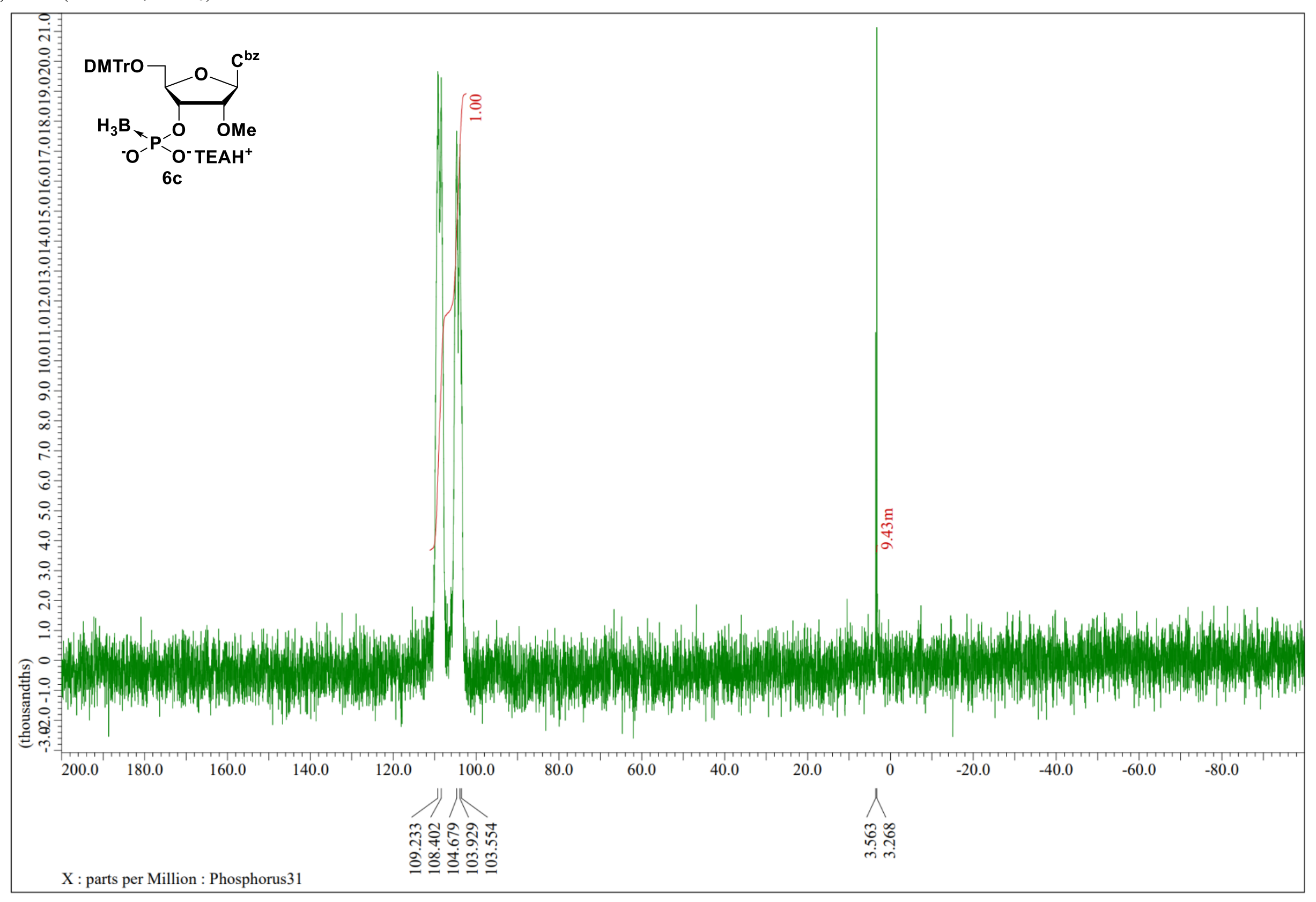


${ }^{1} \mathrm{H}-\mathrm{NMR}\left(400 \mathrm{MHz}, \mathrm{CDCl}_{3}\right.$ )

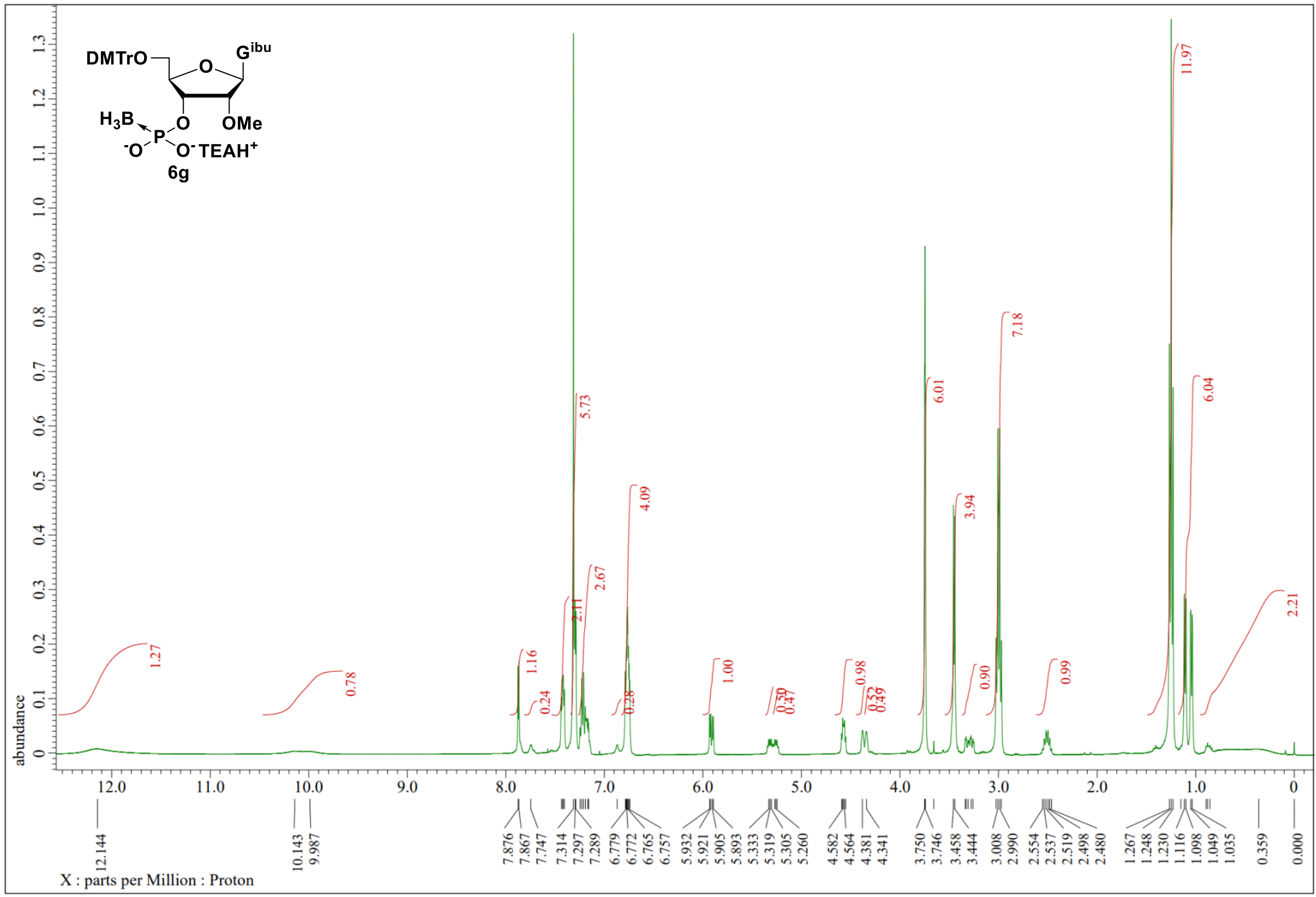


${ }^{13} \mathrm{C}\{\mathrm{H}\} \mathrm{NMR}\left(100 \mathrm{MHz}, \mathrm{CDCl}_{3}\right)$

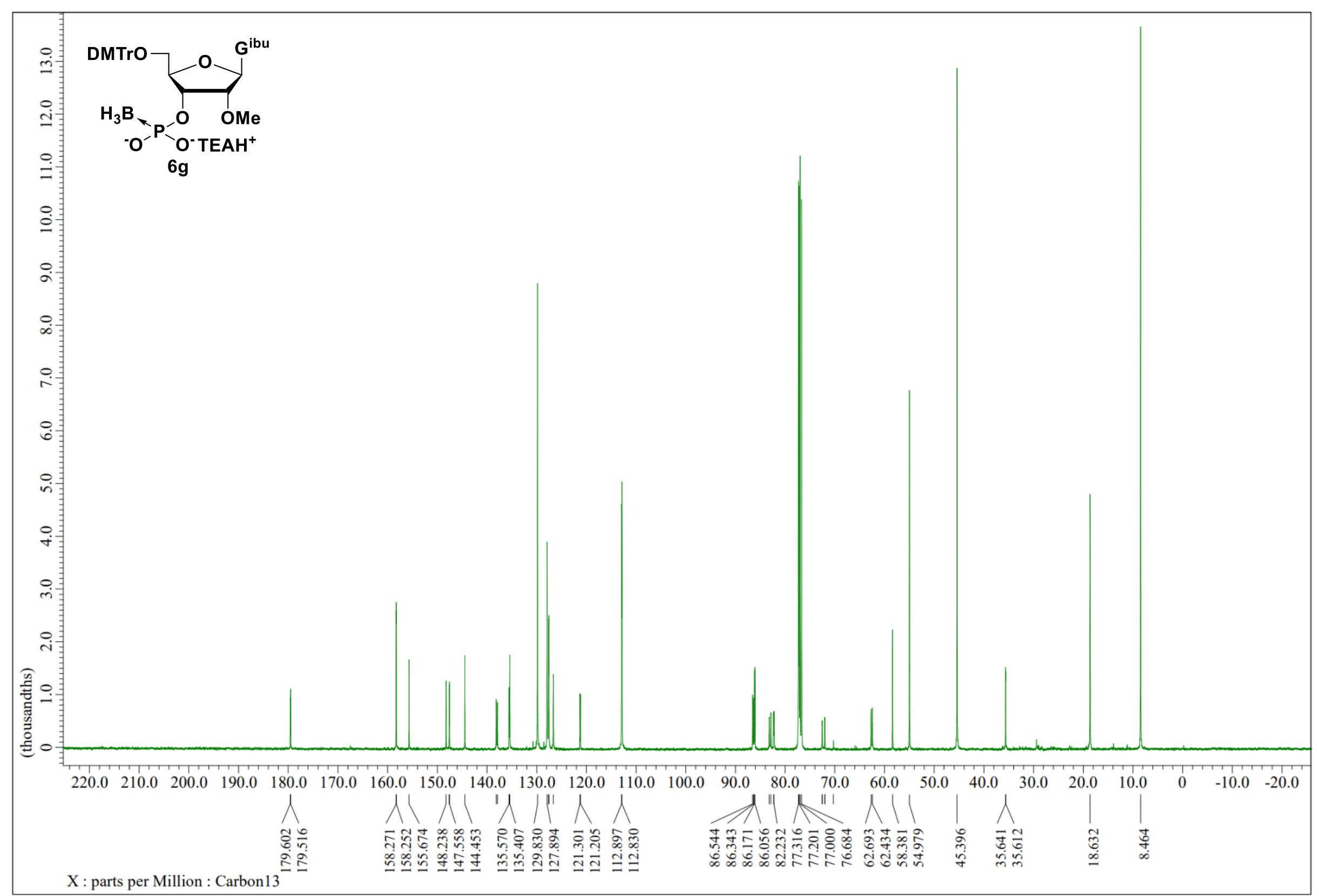


${ }^{31} \mathrm{P}\left\{{ }^{1} \mathrm{H}\right\}$ NMR $\left(162 \mathrm{MHz}, \mathrm{CDCl}_{3}\right)$

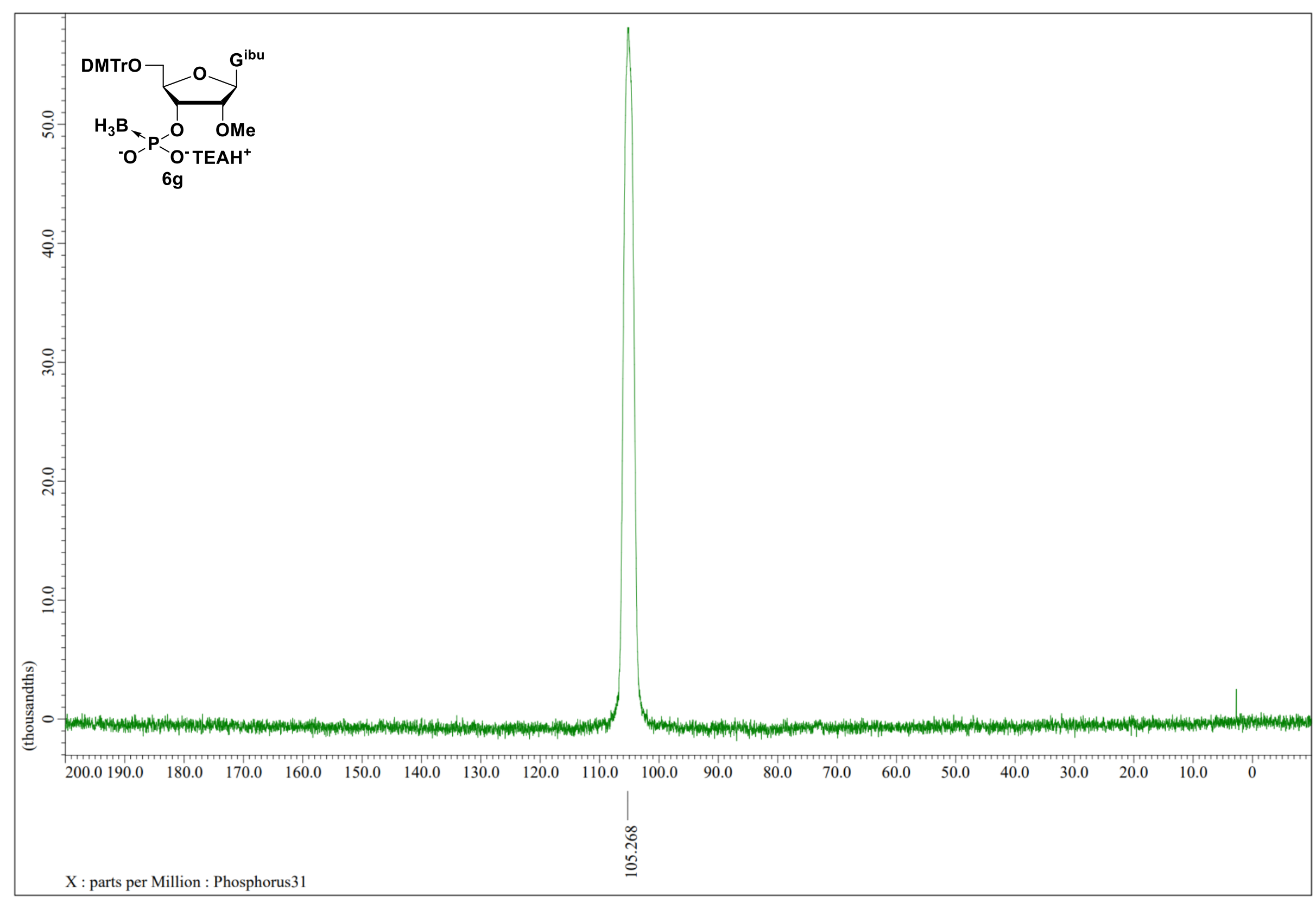


${ }^{1} \mathrm{H}-\mathrm{NMR}\left(400 \mathrm{MHz}, \mathrm{CDCl}_{3}\right.$ )

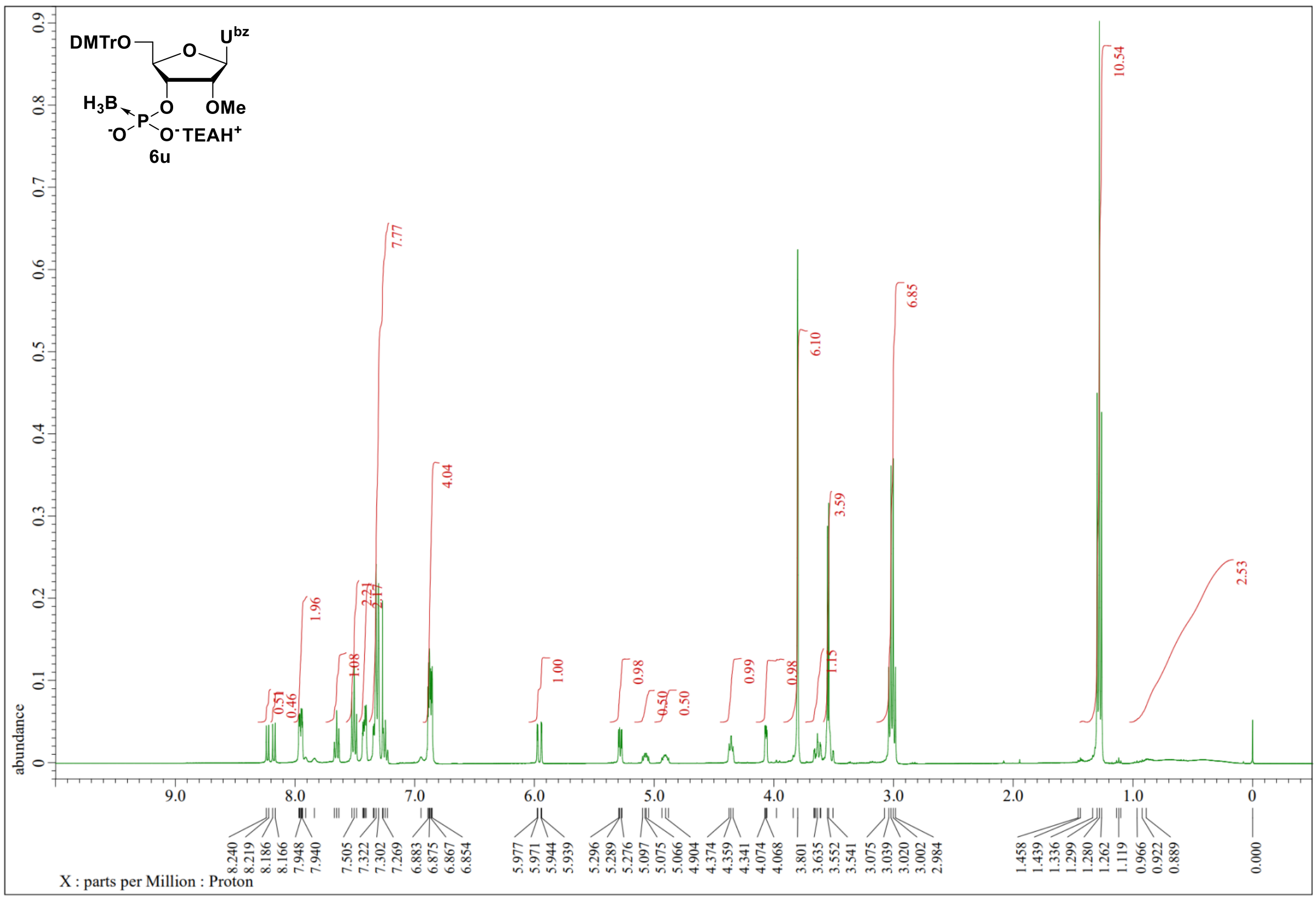


${ }^{13} \mathrm{C}\{\mathrm{H}\} \mathrm{NMR}\left(100 \mathrm{MHz}, \mathrm{CDCl}_{3}\right)$

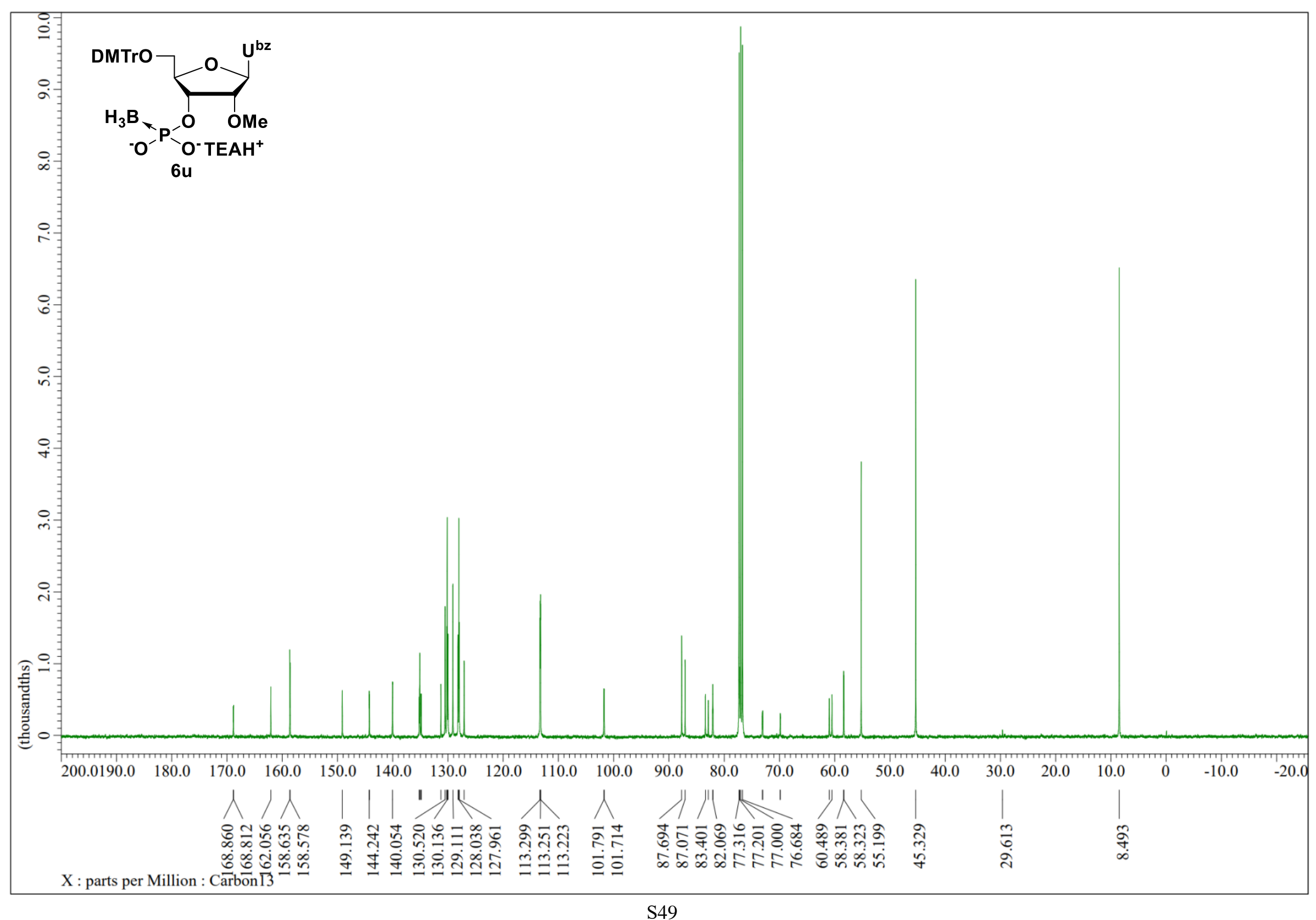


${ }^{31} \mathrm{P}\left\{{ }^{1} \mathrm{H}\right\}$ NMR $\left(162 \mathrm{MHz}, \mathrm{CDCl}_{3}\right)$

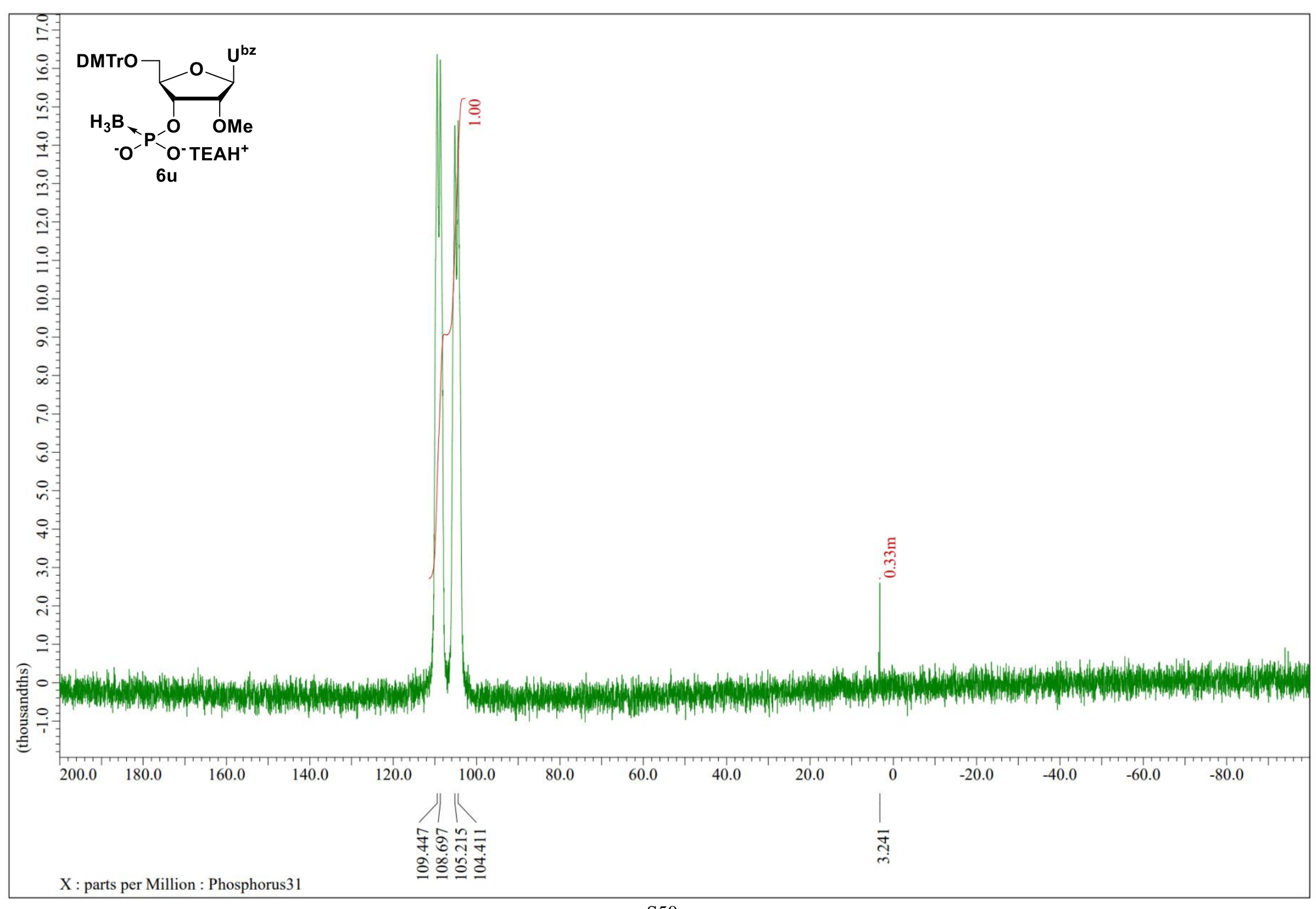

